\title{
Antecedentes, creación y organización escolar del Conservatorio de Música y Danza no estatal de Almería (1982-1987)*
}

\section{Background, creation and school organization of Almería's Music and Dance Non-State Conservatory (1982-1987)}

\author{
Carmen Ramírez Rodríguez \\ Real Conservatorio Profesional de Música de Almería \\ cramrod424@outlook.es \\ ORCID iD: https://orcid.org/0000-0001-8128-6888
}

\section{RESUMEN}

El 19 de enero de 1983, a propuesta del Ministro de Educación y Ciencia, el Consejo de Ministros español reconoció validez académica oficial a las enseñanzas de Grado Elemental del Conservatorio de Música no estatal de Almería. Dependía a efectos económicos y recursos humanos del Consorcio formado entre la Diputación Provincial y el Ayuntamiento de la ciudad por impulso y colaboración de la Asociación de Padres de Alumnos y Amigos proconservatorio de música de Almería. Su actividad cesó el 31 de agosto de 1987. El artículo estudia las instituciones locales de enseñanza musical predecesoras al Conservatorio (Colegio de Seises, Academia de Bellas Artes y Escuela de Artes y Oficios), su proceso fundacional y la organización escolar durante los cursos académicos comprendidos entre 1982 y 1987. Concluye con una visión crítica y comparativa con otros centros andaluces.

Palabras clave: Almería, música y danza, instituciones de educación, conservatorio, organización escolar.

\footnotetext{
* Este artículo se ha realizado gracias a la colaboración de la Hemeroteca Sofía Moreno Garrido y Archivo de la Diputación Provincial de Almería (ADPA), Biblioteca Pública Francisco Villaespesa, Archivo de la Escuela de Arte de Almería (antes, Escuela de Artes y Oficios Artísticos, EAOA), Registro Civil de Almería, Archivo Municipal de Almería (AMA), Archivo de la Catedral de Almería (ACA) y Archivo Histórico Provincial de Almería (AHPA) donde se encuentran las fuentes primarias estudiadas. Asimismo, deseo expresar mi especial gratitud a D. Juan Rigaud Felices y a D. José Ramos Santander por compartir sus testimonios personales.
} 


\begin{abstract}
Upon proposal of the Minister of Education and Science of Spain, the National Board of Education agreed official academic validity for the Elementary Grade in Music and Dance of Almería Non-State Conservatory on 19 January 1983. The human and economic resources were subject to a consortium formed by Provincial and City Council of Almería and the active collaboration of Asociación de Padres de Alumnosy Amigos pro-conservatorio de Música de Almería. It stopped its activity on 31 August 1987. This article examines the education institutions predecessor to Conservatory (Colegio de Seises, Academy of Fine Arts and School of Arts and Crafts), its foundational process and the school organization between 1982 and 1987. It ends with a critical and comparative view with other Andalusian education centres.
\end{abstract}

Key Words: Almería, music and dance, education institutions, conservatory, school organization.

Ramírez Rodríguez, C. (2020). Antecedentes, creación y organización escolar del Conservatorio de Música y Danza no estatal de Almería (1982-1987). Cuadernos de Investigación Musical, 10, pp. 88-119.

Homenaje al profesor José Ramos Santander (1936-2020)

\title{
1. INTRODUCCIÓN
}

Al rebasar el Setecientos, las escasas fuentes documentales conservadas reseñan una ermita caminera ubicada en unos predios de propiedad familiar a las afueras de la Almería amurallada con la imagen de la Virgen de Montserrat. A lo largo del siglo XIX reunió a una creciente devoción labriega y una populosa romería que cada 8 de septiembre, al término de la recolección, partía desde el centro de la ciudad a procesionar y premiar con agasajos, alborozos, cantares y fandangos a la bienhechora hasta que fue saqueada y derruida a comienzos de la contienda civil (Segura del Pino, 2016, pp. 105-108). Hacia 1960, conforme las circunstancias económicas y tecnológicas de la sociedad aportaban nuevos retos por efecto del crecimiento de la demografía y la expansión desmedida urbanística hacia levante, sobre sus cimientos y aledaños, la vega repartió aisladas tapias huertanas, ribazos y extensas llanuras de bancales a los polígonos de San Isidro y Montserrat. A finales de la década de los setenta, de una consecuente segregación y expropiación gradual estatal parcelaria ${ }^{1}$ emergió en unión de la iniciativa privada el distrito de Nueva Andalucía ${ }^{2}$ donde, entre la parroquia de la nueva talla de La Moreneta ${ }^{3}$ y el Instituto de Enseñanza Secundaria “Alborán-Manuel Cáliz”,

\footnotetext{
1 AMA, Expediente 519-3. Almería, 21 de agosto de 1965.

2 Así designó al incipiente barrio la Asociación de Vecinos "Polígono Azcona" al existir varios bloques de edificios con los nombres de capitales andaluzas.

${ }^{3}$ Denominación popular de la Virgen de Montserrat.
} 


\section{CARMEN RAMÍREZ RODRÍGUEZ}

se construyó a instancia de la Consejería de Educación y Ciencia de la Junta de Andalucía ${ }^{4}$ en una superficie cedida por el Ayuntamiento ${ }^{5}$ el inmueble que, afirmando su presencia en altura y compacidad volumétrica, alberga al Conservatorio Profesional de Música y el Conservatorio Profesional de Danza.

De forma rectangular alargada y sobre una superficie de 2.852,90 metros cuadrados, su entorno carecía de tratamiento formal y alineaciones definidas por una normativa específica. Con una calle peatonal, una disparidad de cuerpos y un bloque de seis alturas en la fachada sur colindante entrañó una limitación para la elaboración del proyecto ${ }^{6}-$ Premio Nacional de Arquitectura (1985) ${ }^{7}$ y Premio ARCO $^{8}$ del Colegio Oficial de Arquitectos de Almería (1986-87) - diseñado por el arquitecto, César Ruiz-Larrea Cangas (Madrid, 1950) y codirigido junto al Arquitecto Jefe de la Unidad Técnica de la Delegación Provincial de Educación, Antonio Góngora Sebastián (Almería, 1943). Para resolver una manzana tan caótica, concibió una unidad compositiva de seis plantas destinadas a aulas de danza y en el extremo opuesto, al norte, una torre de siete plantas con las oficinas de dirección y servicios, unidas mediante un cuerpo más bajo de tres plantas que aloja la zona principal de aulas dispuestas sobre una galería exterior cubierta, orientada al oeste o futuro auditorio y plaza pública con palmeras que servirá de vestíbulo urbano al centro y espacio para conciertos al aire libre (Ruiz-Larrea Cangas, 1989, p. 41). La edificación -según reveló e ilustró de forma magistral el arquitecto madrileño en la conferencia ofrecida, el 30 de marzo de 2009, en el centro- tiene un marcado carácter conventual y musical: desnudez de fachadas de ladrillo ocre contrastantes con el suelo blanco de Macael, imitaciones de flautas que a modo de gárgolas sirven de desagüe de las aguas vertidas sobre la cubierta, cajas de resonancia curvilíneas que complementan partes del cuerpo sobre las que reposan, emulaciones de cuerdas superpuestas uniformemente espaciadas así como la modulación geométrica en trama de 5 x 5 denominadora del proyecto «Pentagrama» con cinco líneas horizontales que propinan la pauta rítmica a la disposición.

\footnotetext{
${ }^{4}$ Las obras se iniciaron a comienzos de 1986 y tuvieron un plazo de ejecución de dieciocho meses. (Félix Almarza, 1986: 8).

${ }^{5}$ AMA, Libro de Actas 355 ff. 47-47v. Almería, 7 de noviembre de 1984: «Se acuerda poner a disposición de la Consejería de la Junta de Andalucía la parcela de terreno de propiedad municipal». Cf. Boletín Oficial de la Provincia $\mathrm{n}^{\circ} 192,20$ de agosto de 1986, p. 5.

${ }^{6}$ AMA, Expediente 165. Proyecto básico, pp. 3 y 6. Madrid, 20 de septiembre de 1985.

${ }^{7}$ Fechado y firmado según recoge el acta del Jurado, el 12 de julio de 1985. Se presentaron sesenta trabajos. Fue concedido por unanimidad del jurado al proyecto Pentagrama, correspondiente al arquitecto, César Ruiz-Larrea Cangas, y a los colaboradores, Miguel Ángel Briso Montiano y Juan Manuel Sánchez del Pozo. Integraron el jurado: Juan María Casado Salinas, Director General de Construcciones y Equipamiento Escolar de la Consejería de Educación de la Junta de Andalucía, que actuó como Presidente; Vicente Abad Montoya, Delegado Provincial de la Consejería de Educación en Almería; Luis Pastor Rodríguez, Presidente de la Delegación del Colegio de Arquitectos de Almería; José María Martínez-Oña López, Director del Conservatorio de Música de Almería; Jaime Fesser Pérez de Petinto, Arquitecto de la Dirección General de la Consejería de Educación y Ciencia y Antonio Góngora Sebastián. Cf. Inminente inicio de las obras del nuevo Conservatorio Superior de Música. Ideal, 14 de julio de 1985, p. 18.

${ }^{8}$ La delegación en Almería del Colegio Oficial de Arquitectos de Andalucía Oriental convoca anualmente el Premio ARCO a la mejor obra de arquitectura realizada en la provincia de Almería. Tiene por objeto no solo recompensar el diseño sino también la obra terminada incentivando a todos los ajuntes que intervienen: arquitecto, aparejador, constructor y promotor.

${ }^{9}$ Conservatorio de música, Almería (1986). El Croquis, 26, pp. 80-83; Acién Lirola, 1988, p. 7.
} 
Abrió sus puertas el 6 de noviembre de 1987 impartiendo las enseñanzas elementales y profesionales de Solfeo y Teoría de la Música, Piano, Violín, Guitarra, Clarinete, Conjunto Coral e Instrumental, Armonía y Formas Musicales, Repentización, Transposición y Acompañamiento, Música de Cámara, Estética e Historia de la Música. Sucesivamente se adicionaron las especialidades de Flauta Travesera, Trompeta, Saxofón, Canto $(1991)^{10}$ y bajo su reconocida condición regia, en $1993^{11}$, las de Oboe, Trompa, Trombón, Tuba, (1996) ${ }^{12}$, Viola $(1997)^{13}$, Violonchelo, Fagot, Contrabajo $(1998)^{14}$, Percusión (2000) y Guitarra Flamenca (2007).

La apertura no era ajena a la labor desplegada años atrás por la Asociación de Padres de alumnos y Amigos pro-conservatorio de Música de Almería, a la del profesorado que, desde febrero de 1980, había principiado sus clases en la Academia de Música continuándola a partir del curso 1982/1983 en el instaurado Conservatorio de Música y Danza de Grado Elemental con el patrocinio económico del Consorcio entre la Diputación Provincial y el Ayuntamiento de Almería. Su actividad cesó el 31 de agosto de 1987¹5, donando a la Consejería de Educación y Ciencia los instrumentos musicales, material docente y mobiliario ${ }^{16}$.

La vinculación escolar y docente al conservatorio, su trascendencia como centro formativo y de difusión musical, las lagunas historiográficas y la ausencia de material bibliográfico sobre su etapa fundacional y el funcionamiento primigenio han suscitado el interés por abordarlo en este artículo. Para ello, se ha realizado un sistemático vaciado hemerográfico y documental de los principales archivos y periódicos locales partiendo de las instituciones educativas precedentes y las circunstancias socio-culturales que propiciaron este ambicioso proyecto.

\section{ANTECEDENTES}

\subsection{La ACADEMia DE BELLAS ARTES}

Se gestó por decisión personal del pintor escenógrafo Joaquín Martínez Acosta (Brenes, Sevilla, ca.1865-Almería, 1927). Llegó a Almería en mayo de 1900, a diseñar junto a Manuel Martínez Moya el interior del Teatro-Circo de Variedades, en construcción. Desde entonces, destinó su caudal y empeño a la enseñanza junto a los literatos y periodistas Francisco Aquino, Amador Ramos Oller, Alberto Calderón y Rodolfo Viñas ${ }^{17}$.

El 1 de abril de 1902 abrió sus puertas en el número 13 de la calle Navarro Rodrigo (después Real, 39) con una sección de Pintura y otra de Música para mujeres bajo la dirección

\footnotetext{
${ }^{10}$ Boletín Oficial de la Junta de Andalucía, (BOJA) no 89, 8 de octubre de 1991, p. 8.779.

11 BOJA no 86,7 de agosto de 1993, p. 7.642.

12 BOJA no 93, 13 de agosto de 1996, pp. 10.021-10.022.

13 BOJA n ${ }^{\circ} 108,16$ de septiembre de 1997, pp. 11.409-11.410.

${ }^{14}$ BOJA n $^{\circ} 75,7$ de julio de 1998, p. 8.422.

15 BOJA no 58, 22 de julio de 1988, p. 3.350.

${ }^{16}$ ADPA, Disolución del Consorcio para el Conservatorio Elemental de Música y Danza de Almería. Acta de la sesión ordinaria de 23 de diciembre de 1987, ff. 146-147.

${ }^{17}$ La Alhambra, 306, 15 de diciembre de 1910, p. 12; 15 de noviembre de 1917, p. 14.
} 


\section{CARMEN RAMÍREZ RODRÍGUEZ}

del director de la banda municipal, Enrique Villegas Salafranca ${ }^{18}$. Ofertaron dos modalidades de matriculación: una ordinaria y otra gratuita para obreros, hijos de menestrales y expósitos, sufragada por el consistorio con veintitrés inscripciones anuales y las subvenciones aportadas por el obispo Santos Zárate, los diputados Antonio García Alix y Augusto Barcia Trelles, el Conde de Villamonte, el senador Leopoldo Serrano Domínguez, la Diputación y el Estado (Arpe, 1908, p. 4; Salvador Estrella, 1915, p. 8).

A diferencia de la Escuela de Artes, admitía personas de ambos sexos en secciones completamente diferenciadas, contó con la revista Resurrexit como órgano de expresión, ofertaba diversas especialidades teórico-prácticas e instrumentales y hasta su clausura definitiva, el 4 de enero de 1927, por efecto del fallecimiento del fundador, su labor musical gozó de mayor dinamismo y repercusión en la sociedad, avalado por las referencias en las diferentes crónicas de los reporteros y el prominente índice de participación en actos externos.

En 1910 restablecieron las clases de música, clausuradas desde 1906, por ofrecimiento altruista de varios profesores (Noguera, 1916, p. 1), asumiendo su tutela Gracia Luque Rubio. Sumaron enseñanzas e insertaron nuevas especialidades instrumentales anunciándose impropiamente en la prensa como «Conservatorio de Música» por regirse atendiendo al Plan de Estudios vigente en el de Madrid.

\begin{tabular}{|c|c|c|c|}
\hline \multirow{15}{*}{ ALUMNOS } & INSTRUMENTOS Y ASIGNATURAS & CURSOS & PROFESORES \\
\hline & Solfeo & 3 & $\begin{array}{l}\text { Miguel Álvarez Fernández } \\
\text { Antonio Morel Navarro } \\
\text { Francisco Cruz Oña }\end{array}$ \\
\hline & Armonía y composición & 3 & $\begin{array}{l}\text { Andrés Ramírez Grande } \\
\text { Francisco Barrena Gallego }\end{array}$ \\
\hline & $\begin{array}{l}\text { Violín } \\
\text { Viola }\end{array}$ & $\begin{array}{l}8 \\
8\end{array}$ & $\begin{array}{l}\text { Alfonso Delgado Castilla } \\
\text { Andrés Ramírez Grande } \\
\text { Francisco Barrena Gallego } \\
\text { Francisco Cruz Oña }\end{array}$ \\
\hline & $\begin{array}{l}\text { Violonchelo } \\
\text { Contrabajo }\end{array}$ & $\begin{array}{l}8 \\
6\end{array}$ & José López Grignel \\
\hline & $\begin{array}{l}\text { Flauta } \\
\text { Fagot }\end{array}$ & $\begin{array}{l}6 \\
6\end{array}$ & Ramón Rodríguez Cañadas \\
\hline & Clarinete & 6 & Antonio Morel Navarro \\
\hline & Oboe & 6 & José Rodríguez Cañadas \\
\hline & Cornetín y clarín & 6 & Rafael Camacho Morcillo \\
\hline & Trompeta & 6 & Rafael Camacho Morcillo \\
\hline & Trompa y figle & 6 & Miguel Álvarez Fernández \\
\hline & $\begin{array}{l}\text { Armonium } \\
\text { Canto llano } \\
\end{array}$ & 6 & Andrés Ramírez Grande \\
\hline & Piano & 8 & $\begin{array}{l}\text { Andrés Ramírez Grande } \\
\text { José Sánchez de la Higuera } \\
\text { Antonio Sánchez Punzón }\end{array}$ \\
\hline & Canto & 5 & $\begin{array}{l}\text { Andrés Ramírez Grande } \\
\text { Francisco Barrena Gallego }\end{array}$ \\
\hline & Filosofía de la música & 3 & Alfonso Delgado Castilla \\
\hline \multirow{4}{*}{ ALUMNAS } & Canto & 5 & Andrés Ramírez Grande \\
\hline & Violín & 5 & $\begin{array}{l}\text { Alfonso Delgado Castilla } \\
\text { Francisco Barrena Gallego }\end{array}$ \\
\hline & Solfeo & 3 & Gracia Luque Rubio \\
\hline & Piano & 5 & Gracia Luque Rubio \\
\hline
\end{tabular}

Tabla. 1: Asignaturas, especialidades instrumentales y profesores. Fuente: Elaboración propia a partir del Programa para el curso académico de 1910/1911.

\footnotetext{
18 Academia. La Crónica Meridional, 27 de marzo de 1902, p. 2.
} 
Durante el curso académico de 1913/14 se introdujo una clase de Declamación impartida por el editor Fernando Salvador Estrella, y en 1917, otra de Historia del Arte al frente del escritor Alfonso Delgado Castilla, con presentaciones y disertaciones sobre la historia de la música ${ }^{19}$. A partir de 1916, confiaron parte del recinto al compositor y director del periódico El Día, José Bueno Cordero (Almería, 1867-?), alojándose un colegio preparatorio para el ingreso en las Escuelas Normales de Maestros y Maestras ${ }^{20}$. En su seno nacieron en mayo de 1917, la Sociedad Coral Almeriense con el adiestramiento del profesor Federico Moncada Calvache y la Banda del Hospicio, en julio de 1918, bajo la batuta de Carlos Zósimo Santamaría de Gumier: director del conjunto musical del municipio entre 1916 y $1920^{21}$.

Desde el comienzo, contabilizó una matriculación al alza con amplia hegemonía de alumnado masculino sobre el femenino que acusó un significativo declive por causa de los retraimientos económicos de sus valedores públicos en el curso de 1907/1908²2.

Aunque desconocemos el número inicial de alumnos y matriculados desde 1914 a 1927 en las diferentes especialidades instrumentales, en 1913 era de 62 y componían el 32,63\% del conjunto total que admitió el centro, de los cuales 44 -un 34,64\%- fueron varones y 18 -el $28,57 \%$ restante- hembras con edades comprendidas entre los 9 y 27 años.

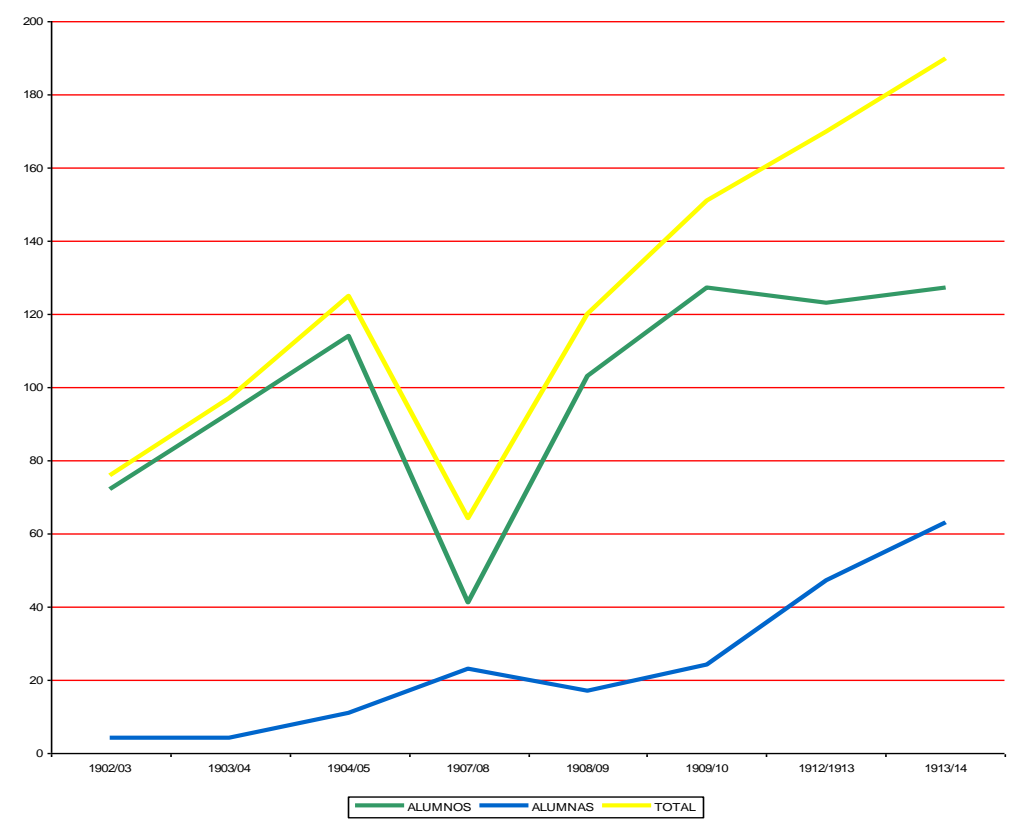

Gráfico 1: Evolución de la matriculación (1902-1914).

Fuente: Elaboración propia a raíz de los datos aportados por Salvador Estrella, 1915 y García Verdejo, 1915 (23 de mayo), pp. 1 y 4.

\footnotetext{
${ }_{19}$ Memoria de la Academia de Bellas Artes. Curso 1913/14. (1915), pp. 6 y 18. En la Academia de Bellas Artes. La Crónica Meridional, 8 de octubre de 1917, p. 2.

${ }^{20}$ El Día, 28 de octubre de 1916, p. 4.

${ }^{21}$ Exámenes. La Crónica Meridional, 25 de julio de 1918, p. 1; La Banda del Hospicio. La Independencia, 16 de julio de 1919, p. 3.

${ }^{22}$ La Academia de Bellas Artes y el Ayuntamiento. Diario de Almería, 22 de mayo de 1924, p. 1.
} 
CARMEN RAMÍREZ RODRÍGUEZ

\begin{tabular}{|cccc|}
\hline CURSOS & ALUMNOS & ALUMNAS & TOTAL \\
\hline $1902 / 03$ & 72 & 4 & 76 \\
\hline $1903 / 04$ & 93 & 4 & 97 \\
\hline $1904 / 05$ & 114 & 11 & 125 \\
\hline $1905 / 06$ & 102 & 18 & 120 \\
\hline $1907 / 08$ & 41 & 23 & 64 \\
\hline $1908 / 09$ & 103 & 17 & 120 \\
\hline $1909 / 10$ & 127 & 24 & 151 \\
\hline $1912 / 13$ & 123 & 47 & 170 \\
\hline $1913 / 14$ & 127 & 63 & 190 \\
\hline
\end{tabular}

Tabla 2: Suma total de matrículas. Fuente: Elaboración propia a raíz de los datos aportados por Salvador Estrella, 1915, p. 17 y García Verdejo, 1915 (23 de mayo), pp. 1 y 4.

Dispusieron el Método Eslava, así como el de Moréy Gil para la enseñanza del solfeo de los alumnos. Las alumnas se instruían con Elprogreso musica ${ }^{23}$. En la última quincena de mayo, cada profesor evaluaba el grado de aprendizaje con las calificaciones de sobresaliente, notable, bueno o suspenso. Concluidos los exámenes podían concurrir a otros ejercicios durante el mes de junio para obtener premios. Eran públicos y la Academia invitaba a personalidades relevantes de la sociedad almeriense a presenciarlos. Las composiciones a interpretar se designaban mediante sorteo y se verificaban ante un tribunal formalizado por tres profesores, el director y el secretario del establecimiento. Por cada diez alumnos aprobados o fracción de dicho número se podía entregar una recompensa o diploma de Primera clase y doble número de credenciales de Segunda. Los compensados con sobresaliente podían optar a conseguir Medallas de Oro, Plata o Bronce ${ }^{24}$.

\subsection{LA ESCUELA DE ARTES Y OFICIOS}

Durante el Parlamento Largo de Sagasta (1886-1890), el diputado por la circunscripción de Almería, Carlos Navarro Rodrigo, relevó al ministro Eugenio Montero Ríos en la cartera de Fomento. Entre sus actuaciones, en 1886 fue creada por Real Decreto de 5 de noviembre la Escuela de Artes y Oficios, una de las siete primeras implantadas en España fuera de la Central ${ }^{25}$. A pesar de la expectación sembrada por los diarios locales, el 9 de diciembre de 1887 principió su biografía con un generalizado escepticismo y desinterés por parte de vecinos y organismos. Sin embargo, poco a poco fue acaparando trascendencia y proyección social sobrepasando hasta el curso de 1931/32 los veintiséis mil estudiantes. En 1909, accediendo a un acuerdo tomado por la Junta de Profesores en la sesión celebrada el 30 de octubre, el Ayuntamiento instauró una clase exclusivamente femenina de solfeo y piano, cuya plaza adjudicó el 13 de noviembre al profesor, Antonio Alonso Guerrero (Almería,

\footnotetext{
23 Academia de Bellas Artes de Almería. Memoria leída con motivo de los exámenes de fin de curso de 192021 por el secretario de este establecimiento. (1922). Almería: Imprenta y papelería Sempere, p. 15.

${ }^{24}$ Exámenes en la Academia de Bellas Artes. La Crónica Meridional, 7 de julio de 1925, p. 6.

${ }^{25}$ Gaceta de Madrid, 6 de noviembre de 1886.
} 
$\left.1876-1936^{26}\right)$, con el sueldo anual de mil quinientas pesetas ${ }^{27}$. Aunque no hemos localizado fuentes documentales donde se describa el contenido de las programaciones o metodología utilizada, por analogía sabemos que para poder cursarla debían ser mayores de doce años, saber leer, escribir y conocer las cuatro reglas de aritmética ${ }^{28}$.

Si la presencia de la mujer en la Escuela se remonta a 1892, se vio privada de formalizar matrícula hasta 1903. A petición de un grupo de ellas y por mediación del alcalde, José María Muñoz, el 3 de noviembre se agregó la «enseñanza artístico-industrial de la mujer» asignada en horario de mañana, con independencia ${ }^{29}$ y totalmente separada de la de los varones hasta 1915. El currículo y programa de asignaturas -Aritmética, Geometría y Contabilidad, Dibujo Geométrico aplicado a las labores y Dibujo Artístico- denotan un contenido de manifiestas connotaciones domésticas y artísticas dirigido a facilitar los conocimientos precisos para ejercer las obligaciones privativas de su sexo. De hecho, la admisión en las aulas del centro fue contemplada como un forzado accesorio ornamental. No obstante, el considerable aumento de matrículas en los sucesivos cursos e inmediatos resultados se encargaron de contrarrestar dicha apreciación contribuyendo eficazmente a reforzar la proyección de esta institución en la sociedad almeriense (Sánchez Cañadas, 2004, p. 69). Precisamente, fue la asignatura de "Música y Piano" una de las que mayor aceptación y demanda -no excluida de oscilaciones- recibió desde su inserción. Si bien, al no ser una de las materias para las cuales estaban concebidas las Escuelas de Artes, nunca superó los límites del 5\% respecto al volumen total de la red de escolaridad que ofertaba.

En el curso 1911/12 disminuye la matrícula a casi la mitad de alumnas. Recupera la cota preliminar entre 1913-1917, estabilizándose de forma aislada, en 1925, con una media de 38,15 inscripciones anuales.

\footnotetext{
${ }^{26}$ Registro Civil de Almería, Sección $3^{\text {a }}$ del Tomo 163, p. 601.

27 Archivo de la EAOA. Libro de personal, p. 113; Los presupuestos municipales. El Radical, 14 de noviembre de 1909 , p. 1.

28 Art. 46 del Real Decreto y Reglamento Orgánico para las Escuelas de Artes Industriales y de Industrias, 6 de agosto de 1907, p. 49.

${ }^{29}$ La enseñanza en Almería. El Radical, 1 de octubre de 1907, p. 1; Enseñanza para la mujer. La Crónica Meridional, 23 de octubre de 1903, p. 2.
} 


\begin{tabular}{|c|c|c|c|c|c|c|}
\hline CURSOS & Matriculadas & Sobresalientes & Notables & Aprobadas & Total aptos & No presentadas \\
\hline $1909 / 10$ & 63 & 1 & 7 & 6 & 14 & 49 \\
\hline $1910 / 11$ & 67 & & & & 17 & 50 \\
\hline $1911 / 12$ & 36 & 4 & 3 & 9 & 16 & 20 \\
\hline $1912 / 13$ & 43 & 7 & 3 & 8 & 18 & 25 \\
\hline $1913 / 14$ & 60 & 3 & 8 & 11 & 22 & 38 \\
\hline $1914 / 15$ & 50 & 3 & 8 & 18 & 29 & 21 \\
\hline $1915 / 16$ & 74 & 3 & 12 & 28 & 43 & 31 \\
\hline $1916 / 17$ & 50 & 3 & 4 & 32 & 39 & 11 \\
\hline $1917 / 18$ & 53 & 4 & 6 & 11 & 21 & 32 \\
\hline $1918 / 19$ & 46 & 3 & 3 & 10 & 16 & 30 \\
\hline $1919 / 20$ & 37 & 2 & 2 & 29 & 33 & 4 \\
\hline $1920 / 21$ & 32 & 3 & 4 & 8 & 15 & 17 \\
\hline $1921 / 22$ & 35 & 4 & 1 & 3 & 8 & 27 \\
\hline $1922 / 23$ & 24 & 4 & & 5 & 9 & 15 \\
\hline $1923 / 24$ & 43 & 2 & 3 & 7 & 12 & 31 \\
\hline $1924 / 25$ & 46 & 2 & 2 & 2 & 6 & 40 \\
\hline $1925 / 26$ & 55 & 2 & 8 & 8 & 18 & 37 \\
\hline $1926 / 27$ & 41 & 3 & 4 & 1 & 8 & 33 \\
\hline $1927 / 28$ & 35 & 3 & 2 & 11 & 16 & 19 \\
\hline $1928 / 29$ & 33 & 4 & 5 & 4 & 13 & 20 \\
\hline $1929 / 30$ & 39 & 4 & 3 & 5 & 12 & 27 \\
\hline $1930 / 31$ & 30 & 2 & 2 & 6 & 10 & 20 \\
\hline $1931 / 32$ & 49 & 2 & 6 & 9 & 17 & 32 \\
\hline TOTAL & 1041 & 68 & 96 & 231 & 412 & 629 \\
\hline
\end{tabular}

Tabla 3: Música y piano. Matrículas y calificaciones entre los cursos 1909/10-1931/32.

Fuente: Elaboración propia a partir de las Memorias de la EAOA. Cursos 1909/10-1931/32.

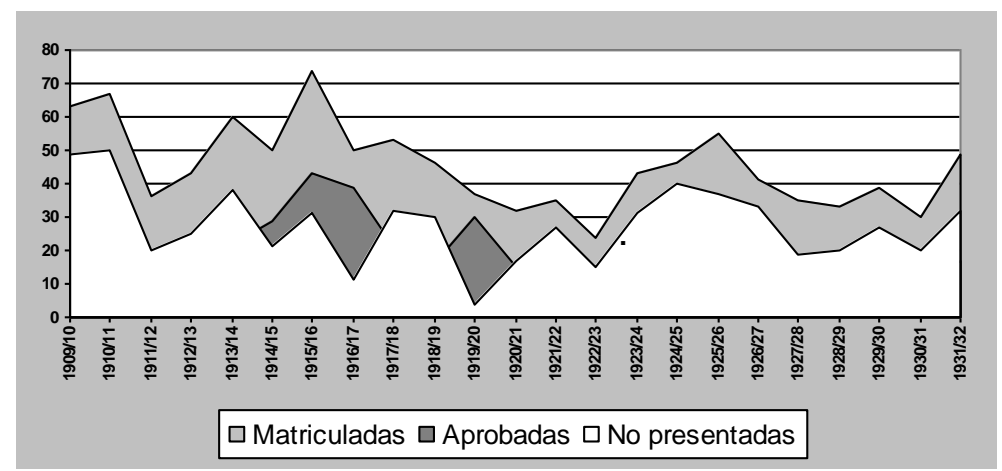

Gráfico 2: Evolución de alumnas matriculadas-examinadas-aprobadas.

Fuente: Elaboración propia a partir de las Memorias de la EAOA. Cursos 1909/10-1931/32.

La explicación a esta intermitencia podríamos justificarla basándonos en tres consideraciones: de un lado, el efecto novedoso que toda primicia engendra consigo generalmente advertida en los dos primeros cursos, suplantada con el devenir por un número más reducido de personas verdaderamente interesadas en su aprendizaje; de otro, la inclusión de dicha enseñanza en la Academia de Bellas Artes a partir de 1910; y por último, la decadencia económica divisada a comienzo de los años veinte en la provincia a partir de la culminación bélica europea. 


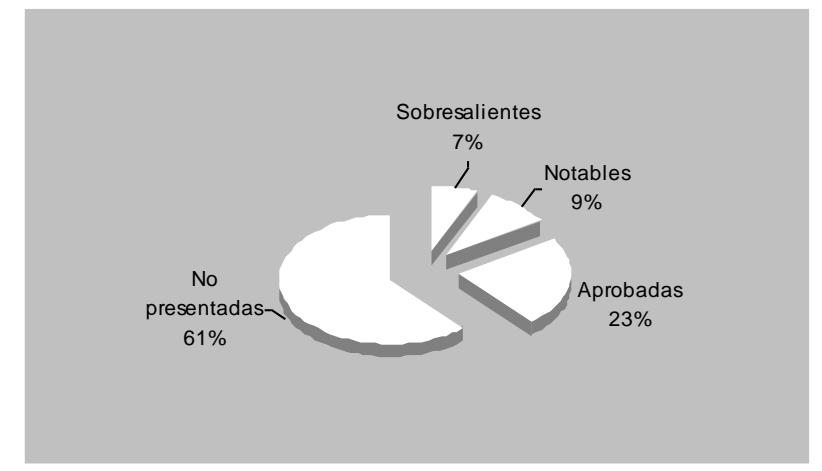

Gráfico 3: Porcentaje de examinadas y calificaciones.

Fuente: Elaboración propia a partir de las Memorias de la EAOA. Cursos 1909/10-1931/32.

Globalmente, el porcentaje de alumnas que concurren a examen es bajo $(39,57 \%)$. De las 1.041 matriculadas en este período, 629 no se examinaron $(60,42 \%)$, lo cual indica que algo más de la mitad abandonaban los estudios o asistían a clase sin tener la intención de recibir a cambio una calificación ya que, a la postre, la Escuela no reunía los requisitos para expedir titulaciones y los estudios musicales cursados carecían de validez académica.

Solamente podía librar una certificación de asistencia y, a las evaluadas, una de aprovechamiento con la calificación obtenida. De las 412 restantes, todas consiguen resultados positivos con una sistemática omisión del suspenso. Únicamente, deducimos, comparecían a examinarse cuando, aconsejadas o disuadidas por el profesor, existe la certeza de aprobar. Su criterio es decisivo por razón de un incipiente concepto interno de evaluación continua. Debía hacer un seguimiento diario en atención al grado de aplicación, asistencia, puntualidad y comportamiento. En virtud del progreso, al término del curso se reconocía con diplomas sin percibir, como en el caso de los obreros, cantidades en metálico. Para paliar de alguna forma esta recompensa y con el fin de incentivar su aprovechamiento, la Escuela convocaba anualmente un concurso de piano al cual exclusivamente podían presentarse las inscritas oficialmente en dicha enseñanza previa autorización del profesor. Se designaba una obra obligada y la sesión pública tenía lugar en el mes de mayo ante un jurado compuesto por el instructor de la asignatura y otros dos del centro adjudicándose un premio a la alumna que "demostrase mayores conocimientos y más ejecución” y un accésit a la que le siguiese en méritos ${ }^{30}$.

\subsection{El COLEGio De SEISES}

Desde 1576, el capítulo XXVII de la Consueta que el Cabildo catedralicio debía acatar, exigió al maestro de capilla enseñar canto de órgano a todos los que quisieran aprender gratuitamente por espacio de una hora diaria a continuación del rezo de Completas exceptuando los festivos ${ }^{31}$. La oposición medieval de la Iglesia católica -con mayor o menor

\footnotetext{
30 Un concurso. La Independencia, 21 de enero de 1912, p. 1.

31 ACA. Consueta de la Santa Iglesia Catedral de la ciudad de Almería que deben observar el Ilustrísimo Señor Deán y Cabildo de ella y todos los demás Ministros, 1761, p. 41.
} 
flexibilidad según las épocas y lugares- a que las voces femeninas entonasen en recintos y actos religiosos fue compensada por niños que ingresaban en calidad de seises. Por razones fisiológicas, su estadía era breve y al mudar la voz pasaban a ocupar otro desempeño vocal o instrumental (López Martín, Bonillo Navarro, Requena García, 1997, p. 156). La reducción de individuos en el coro proveniente del progresivo empobrecimiento decimonónico de la Fábrica Mayor, obligó a restringir el ofrecimiento de plazas anunciándose meramente cuando sobrevenía alguna vacante. Además de concurrir a todas las solemnidades, debían asistir al coro diariamente en horario de mañana y tarde $e^{32}$. Las travesuras y constantes faltas de asistencia fueron causas reiteradas de despidos, renuncias y readmisiones propiciando un descenso y, a partir de la primera década del Novecientos, su extinción.

Para atender al ornato de la liturgia, la acción del celebrante en la misa, la instrucción y el fomento de la música sagrada, en enero de 1919, el obispo Vicente Casanova y Marzol (1908-1921) fundó un Colegio de Seises que puso al frente del deán Antonio Prieto Poupariña (San Juan de Alba-Villalba, Lugo, 1864-Burgos, 1934). Nombraron director musical al maestro de capilla Manuel García Martínez (Jaca, Huesca, 1884-Almería, 1928) ${ }^{33}$. Su origen aragonés no le impidió asimilar las tradiciones almerienses hasta convertirse en figura de referencia para la música urbana al ceder partituras al Himno del Regimiento de la Corona y al de Almería, escritos por el canónigo Joaquín Peralta Valdivia ${ }^{34}$ y el poeta Antonio Ledesma Hernández, correspondientemente. Estimaciones que le valieron para que el rey Alfonso XIII le concediera la Cruz de Primera Clase del Mérito Militar y el ayuntamiento, a instancia del presidente de festejos, José García del Moral, lo nombrase hijo adoptivo ${ }^{35}$.

Las condiciones de admisión al Colegio fueron tener edades contenidas entre los siete y doce años, saber leer y escribir, poseer una constitución saludable y una extensión de la voz, de do a sol agudo. Retribuirían a los elegidos por su asistencia al coro dotándoles de libros y material pedagógico. Seleccionaron medio centenar de niños de voz timbrada y comenzó en una triple vertiente: Letras primarias, Enseñanzas Profesionales del Comercio con clases de taquigrafía, mecanografía, contabilidad y cálculo mercantil por los Padres Juan Aguilar, Juan Asenjo y Juan López Suárez; y formación musical. Se dio solfeo y canto ampliándose con el aprendizaje y práctica de los instrumentos de la capilla. Las clases de violín las impartieron, el director de la Banda del Regimiento de la Corona -Ricardo Quiroga Marcos-, Francisco Cruz Oña (Almería, 1888-1959) y Francisco Sánchez López. Las de flauta, Manuel Sánchez Piñón. El subdirector de la agrupación castrense, Ricardo Sevilla Fuster (Cartagena, Murcia, 1887-1948), enseñaba fagot, trompa y trompeta. Y el organista de la catedral, Abelardo Campra Fuentes, se encargó del piano ${ }^{36}$.

\footnotetext{
32 ACA. Libro de Actas Capitulares 71, ff.195v-196r.

${ }^{33}$ En diciembre de 1905, fue nombrado organista segundo y el 5 de abril de 1909 opositó y accedió a la plaza de Maestro de Capilla. Para ello, repentizó un Laudate Dominum, interpretó una Salve de su inventiva y dirigió a primera vista los Kiries de la Misa de Antonio Palancar, a cuatro voces, órgano y orquesta. El tribunal lo formaron: Felipe Tarancón, Chantre; Joaquín Peralta Valdivia, Penitenciario; Arturo Menan, Lectoral; Juan Domínguez, organista; Antonio Sánchez y Andrés Ramírez, Salmistas. Véase: Oposiciones. La Crónica Meridional, 6 de abril de 1909, p. 2.

${ }^{34}$ En el Cuartel. El acto de ayer. La Crónica Meridional, 7 de mayo de 1920, p. 4.

${ }^{35}$ Diario de Almería, 4 de febrero de 1917, p. 1; En el Ayuntamiento. La Crónica Meridional, 17 de octubre de 1916, p. 2.

${ }^{36}$ Historias almerienses. La Voz de Almería, 27 de febrero de 1977, p. 11.
} 
La privación de las actas posteriores a 1916 nos ha impedido estudiar la trayectoria de la escolanía. Sin embargo, la hemerografía coetánea desvela el catálogo de obras entonado con el refuerzo ocasional de la Schola Cantorum del Seminario de San Indalecio que dirigía el Superior, Buenaventura Pujol Marín, caracterizado por la preferencia de autores españoles del XIX de este género.

\begin{tabular}{|c|c|}
\hline \multicolumn{2}{|c|}{ REPERTORIO (1919-1928) } \\
\hline COMPOSITOR & COMPOSICIONES \\
\hline \multirow[t]{2}{*}{ ANTONIO MARCO } & Lamentaciones $2^{\mathrm{a}}$ y $3^{\mathrm{a}}$ \\
\hline & Misa de Pontificial In Laudem Divi Augustini \\
\hline COSME JOSÉ DE BENITO & Pasión a cuatro voces, órgano y orquesta \\
\hline GIUSEPPE CONCONE & Misa a cuatro voces, piano y acompañamiento de orquesta \\
\hline \multirow[t]{5}{*}{ HILARIÓN ESLAVA } & Sequentia Lauda Sion \\
\hline & Misa en Mi bemol y a cinco voces \\
\hline & Miserere \\
\hline & Motete a cuatro voces y orquesta \\
\hline & Victime Paschalis \\
\hline IGNACIO BUSCA DE SAGASTIZÁBAL & Misa de Pascua a dos voces y coro \\
\hline J. VERGÉS & Lamentaciones $1^{\mathrm{a}}, 2^{\mathrm{a}}$ y $3^{\mathrm{a}}$ \\
\hline JOSÉ CABAS GALBÁN & Misa \\
\hline JOSÉ RIVERA & Misa de Sacramento a cuatro voces, órgano y orquesta \\
\hline JUAN BAUTISTA GUZMÁN & Miserere \\
\hline JUAN CANSINO & $\begin{array}{l}\text { Las Siete Palabras a cuatro voces, órgano, solos y orquesta } \\
\text { (Estreno: Viernes Santo de 1928) }\end{array}$ \\
\hline JULES BRAZIL & Misa con acompañamiento de armonium y dos órganos \\
\hline JULIÁN VILASECA & Misa coral de Pío X a una voz y coro a tres voces \\
\hline LOUIS DE MERLIER & Misa en La \\
\hline L. V. BEETHOVEN & Motete a cuatro voces y orquesta \\
\hline \multirow[t]{3}{*}{ MANUEL GARCÍA MARTÍNEZ } & Misa a cuatro voces, órgano y orquesta \\
\hline & Gloria et Laus a cinco voces solas \\
\hline & Responsorios \\
\hline RAMÓN GARAY & Chistus factus \\
\hline \multirow[t]{3}{*}{ TOMÁS LUIS DE VICTORIA } & En la Adoración de la Cruz. \\
\hline & Christus factus \\
\hline & Popule meus a cuatro voces, órgano, solos y orquesta \\
\hline VICENTE PALACIOS & Miserere \\
\hline WERNER & Motete a cuatro voces y orquesta \\
\hline
\end{tabular}

Tabla 4: Repertorio (1919-1928).

Fuente: Elaboración propia a partir de la hemerografía consultada.

Esta institución se dispersó cuando parecía destinada a perdurar. El traslado del deán a Jaén y la repentina muerte del maestro de capilla, el 31 de diciembre de 1928 (Escámez Mañas, 2015, p. 646), no encontraron sucesores al entusiasmo que transmitieron al centro. 


\section{Creación del Conservatorio de Música y Danza no estatal de Almería}

\subsection{CONATOS Y CONTINGENCIAS}

Laborioso, lento y no exento de tentativas fallidas fue el proceso. Bajo la denominación de Filarmónica Almeriense ${ }^{37}$ constituyeron una sociedad en julio de 1934 al objeto de estimular -según reza el primero y segundo de sus artículos- el desenvolvimiento musical entre la población capitalina organizando recitales y conferencias e instaurando un conservatorio donde dimanasen una orquesta y un coro, regido por un reglamento que confeccionaría la Junta de Gobierno ${ }^{38}$. La proposición captó de inmediato numerosos simpatizantes ${ }^{39}$. Un año después, y teniendo presente que la enseñanza mercantil surgió en el seno del Conservatorio madrileño de Artes y Ofícios en 1824 (Gómez Díaz, 2001, p. 240), cuando irrumpe la Escuela Oficial de Comercio, la prensa publica que la instalación de una Universidad o Conservatorio de Música y Declamación sería bien acogida por los almerienses ${ }^{40}$. Sendas aspiraciones quedaron en el papel al precipitarse la ofensiva del 36.

La industria cinematográfica y un paulatino resurgimiento cultural preludiaron el ecuador del siglo. La Academia de Música de la Falange Española ${ }^{41}$, las lecciones de piano y las de canto impartidas alternativamente por Emilia García Abad en el número 21 de la Calle de la Reina y, desde 1955, por la soprano, Asunción Giraldez (Bilbao, 1921-Vera, Almería, 2011), en la Escuela de Artes cubrieron las nacientes inquietudes musicales. Los conciertos dominicales de la Biblioteca Villaespesa, las actuaciones del Cuarteto -a continuación, Quinteto Clásico Municipal- integrado por el pianista Rafael Barco (Fuente Victoria, Almería, 1903-Almería, 1995), los violinistas Francisco Cruz Oña y Antonio Cuadra (Alhabia, Almería, 1910-Almería, 2004), la violonchelista chilena Pilar Cela y Francisco Sánchez a la viola ${ }^{42}$ relevaron la propagación de composiciones clásicas pretéritas de autoría europea y coetáneas españolas que, entre 1923 y 1933, acometiera la delegación de la Asociación de Cultura Musical (López Marinas, 2009, pp. 294-317). Los Festivales de España, las programaciones musicales de Radio Almería, Radio Juventud y Radio Popular o la primera edición del Festival de Danzas del Mediterráneo, en 1957, completaron aquel proceso de socialización e internacionalización. Y cuando la España de la postguerra se afanaba en desbaratar obstáculos e incomprensiones, la música y el baile enarbolaron su bandera de reconciliación asentando una embajada estética al otro lado de nuestras fronteras. Al cometido de recuperación y difusión de bailes, indumentarias, canciones del folclore y fuentes populares hispanas con valor reivindicativo de la identidad patria (Casero García, 2000, pp. 62-66) que la Sección Femenina ${ }^{43}$ cedió desde 1951 a través de sus Grupos de Danzas

\footnotetext{
${ }^{37}$ Filarmónica almeriense. Heraldo de Almería, 18 de julio de 1934, p. 1.

38 AHPA, signatura 4399-30. Estatutos de la Filarmónica almeriense. Almería, 21 de mayo de 1934.

${ }^{39}$ La Filarmónica Almeriense. La Crónica Meridional, 13 de julio de 1934, p. 2.

${ }^{40}$ La Escuela Oficial de Comercio. Diario de Almería, 5 de abril de 1935, p. 1.

${ }^{41}$ Falange española tradicionalista y de las JONS. Yugo, 31 de julio de 1942, p. 6.

42 El quinteto municipal de la Biblioteca Villaespesa. Yugo, 4 de enero de 1951, p. 8.

${ }^{43}$ La visualización del Estado aglutinador de diversas regiones e idiomas a través de la música, la representación de la identidad nacional en el extranjero, la admiración y el respeto hacia el tradicionalismo y catolicismo transmitieron el mensaje ideológico de su fundadora y presidenta: Pilar Primo de Rivera. Cit. por Castañón Rodríguez, 2012, p. 103.
} 
(Rodríguez López, 2005, pp. 185, 713 y 747) se unió con posterioridad el cuadro artístico de Amigos de la Música, el Septeto de guitarras Manuel de Falla-combinado por los hermanos Francisco Luis y Jesús Miranda Hita, Marie Thérèse Olivier, Natividad González Rivera, Francisco Valverde, Emilio Leseduarte y José Alias Salvador ${ }^{44}$-, la rondalla, la Academia de Solfeo y el Grupo de Coros y Danzas Virgen del Mar de la Organización Sindical de Educación y Descanso con sede en el Teatro Apolo. Bajo la dirección musical y coreográfica del guitarrista, José Fernández Campos «Richoly» (Adra, Almería, 1920-Almería, 1995), parrandas, robaos, farrucas, peteneras, soleares y el Fandanguillo de Almería, de Gaspar Vivas (Almería, 1872-1936), alternaron con el cante de José Sorroche, las melodías de Ángel Barceló y Manuel del Águila, los montajes y pasos de la Estampa marinera o la de la Virgen del $\mathrm{Mar}^{45}$ en exhibiciones provinciales y escenarios internacionales de Alemania, Colombia, Marruecos, Bélgica, Francia e Inglaterra.

La falta de medios económicos de algunos aficionados a la música impedía beneficiarse de las vocaciones artísticas con el preciso control educacional y el ayuntamiento recurría a las compañías de ópera y zarzuela que visitaban eventualmente la localidad o a instrumentistas militares y foráneos para completar la Banda del municipio. La voz de su director, Eusebio Rivera Sánchez (Salamanca, 1889-Valencia, 1961), aunada a las del compositor Francisco Vicente o el violinista Antonio Cuadra, clamaban la instauración de una entidad oficial musical como preámbulo a un conservatorio. Para ello -añadió Richoly, en mayo de 1953- debemos contar con la colaboración de las autoridades y exponer en Madrid la importancia del bosquejo que se ha trazado ${ }^{46}$.

Se dilató en el tiempo y el fundador de la Agrupación Coral Almeriense, Emilio Carrión Fos (Valencia, 1921-Madrid, 1981), abrió el diálogo semanal del viernes en las Tertulias Indalianas $^{47}$ del 71 con la veterana aspiración ${ }^{48}$. Desde las páginas de La Voz de Almería, el compositor Rafael Barco Molina, el empresario Luis Gázquez Morata o la profesora de danza Amelia del Águila Fernández ${ }^{49}$ la secundaron porque anualmente centenares de jóvenes

\footnotetext{
${ }^{44}$ Hicieron su debut el 22 de agosto de 1973 en la Escuela de Artes y Oficios. «Concierto de presentación de la Agrupación de Guitarras de la Obra Sindical Educación y Descanso "Manuel de Falla". La Voz de Almería, 23 de agosto de 1973, p. 2.

${ }^{45}$ Los grupos folklóricos de la región se preparan en Almería, Almería. Ideal, 10 de marzo de 1973, p. 11; Almería escenificará la estampa Virgen del Mar en la Romería Andaluza. La Voz de Almería, 28 de abril de 1973, p. 3.

${ }^{46}$ La creación de un Conservatorio de música en Almería. Yugo, 26 de abril de 1953, pp. 1 y 6; La instalación de un conservatorio es algo de necesidad inmediata. Yugo, 23 de mayo de 1953, pp. 1 y 6.

${ }^{47}$ En enero de 1971, un grupo local encabezado por el sacerdote, Bartolomé Marín, reanudó los propósitos culturales de la antigua Tertulia Indaliana (anteriormente denominada Tertulia de Artistas y Escritores), fundada por el pintor y escultor almeriense, Jesús de Perceval, en 1945 con vigencia en los años cincuenta. Reunió a artistas, científicos, historiadores, literatos, humanistas y acreditadas figuras de la vida nacional, atraídos por la diversidad temática. Cf. Bocero García, 2009, p. 62.

48 Tertulia indaliana. La Voz de Almería, 23 de junio de 1971, pp. 2 y 11.

${ }^{49}$ El maestro Barco. Necesitamos un conservatorio. Ideal, 1 de octubre de 1972, p. 7; La enseñanza de la música en Almería. La Voz de Almería, 20 de marzo de 1971, p. 12; La Voz de Almería, 25 de julio de 1974, p. 13; Masegosa Requena, J. L. «Escuela de Danza Amelia del Águila», La Voz de Almería, 5 de julio de 1979, pp. 1213.
} 


\section{CARMEN RAMÍREZ RODRÍGUEZ}

recorrían kilómetros para alcanzar la meta deseada: un 30\% se examinaba en el Conservatorio de Murcia; el 10\% lo hacía en el de Granada y en menor porcentaje acudían al de Málaga ${ }^{50}$.

\subsection{LA ASOCIACIÓN DE PADRES DE ALUMNOS Y AMIGOS PRO-CONSERVATORIO DE MÚSICA DE ALMERÍA}

La iniciación del Colegio Universitario de Almería (1972), los encuentros en la Galería Haryy, la divulgación del flamenco desde el Taranto, la organización de la Asociación Filarmónica de Almería (AFA) o la reorganización del Ateneo (1974), los conjuntos juveniles que dirigió el Hermano Emilio Salado, el lanzamiento del Grupo de Canto de la Universidad Laboral y las primicias del «Georgia Jazz Club» (Blanco Martín, 2015, p. 275) preludiaron una ruta de mentalización colectiva a lo largo de cuatro años, entreverada de perseverancia y tramitaciones que favorecieron el 19 de diciembre de 1979 la constitución de la Asociación de Padres de alumnos y Amigos pro-conservatorio de Música de Almería $a^{51}$. Presidió la comisión gestora el empresario Juan Rigaud Felices, incluyéndola: Jesús Olmo Gómez (vicepresidente), María del Carmen Soler Rodríguez (secretaria), Miguel García de los Ríos (vicesecretario), Ana García Martínez (tesorera) y los vocales Ramón Muñoz Sánchez, Joaquín Pérez Alba (que actuaba a su vez como contador), Manuel Rodríguez Martínez, María del Mar Batlles Campos y Leopoldo Pérez Torrecillas ${ }^{52}$.

Al espíritu innovador, siempre elegante, de mejora constante por y para Almería que llevaron a Rigaud a fundar "Glady's Boutique" en la década de los sesenta se fundió su pasión por la pintura y la música con la colaboración que prestaron estos profesionales de la medicina, la abogacía y la docencia agrupada por más de cien inscritos, a fin de:

- Crear una comunidad de inquietudes que permitiese el establecimiento en Almería de un conservatorio de música.

- Trabajar con los organismos oficiales y otras entidades públicas y privadas en la organización de una programación de actividades culturales y musicales ${ }^{53}$ encaminada a la formación integral de los socios $\mathrm{y}$;

- Colaborar con los centros de EGB, BUP, COU, Formación Profesional y Colegio Universitario en la difusión de la cultura musical ${ }^{54}$.

Las gestiones del Director General de Personal del Ministerio de Educación y Ciencia en Madrid, Fernando Lanzaco Bonilla (Madrid, 1938) ${ }^{55}$, y las del Delegado Provincial de Educación y Ciencia de Almería, José Ramos Santander (Linares, Jaén, 1936-Almería, 2020), fueron cruciales. Pedagogo, licenciado en Derecho y Filosofía, impulsor de las Letras,

\footnotetext{
${ }^{50}$ La calle. La Voz de Almería, 6 de enero de 1978, p. 12.

${ }^{51} \mathrm{La}$ Asociación se registró el 21 de enero de 1980, con número 271 y sede en el Paseo de Almería, 32.

52 Acta de constitución de la Asociación de Padres de alumnos y Amigos pro-conservatorio de Música de Almería. Salón de Actos de la Escuela de Arte y Oficios de Almería, 19 de diciembre de 1979.

53 Véase al respecto, Apéndice no II. Tabla 11. Actividades culturales y musicales.

${ }^{54}$ Artículo 2. Estatutos de la Asociación de Padres de Alumnos y Amigos pro-conservatorio de Música de Almería. Almería, 1979, p. 1.

${ }^{55}$ Había sido Delegado Provincial de Educación y Ciencia en Almería entre junio de 1969 y febrero de 1971.
} 
inspector entre 1970-1977 e Inspector Jefe desde 1983 a $1996^{56}$ al posesionarse del compromiso provincial, en diciembre de $1977^{57}$, logró a lo largo de los cinco años siguientes garantizar la escolaridad en anejos y poblaciones apartadas de los mapas llevando a la circunscripción a adquirir el porcentaje más elevado de inversiones en infraestructuras docentes por habitante del país ${ }^{58}$. Coincidiendo con la transferencia de responsabilidades y patrimonio de algunos sectores desde el Ministerio de Educación y Ciencia al de Cultura, el 24 de abril y 16 de mayo de 1978, oficializó la petición de creación de un Conservatorio Elemental de Música dependiente del Ministerio ${ }^{59}$. Seguidamente, propiciaron la autorización de una cátedra ambulante ${ }^{60}$ por extensión del Conservatorio Superior de Música de Murcia bajo la coordinación de su director, Manuel Massotti Littel, erigida por los catedráticos y profesores: Fernando García Escobar, Miguel Baró Bo, Anselmo Espinosa del Águila (Piano), Ginés Abellán Alcaraz, Marina Payans Alcaraz, Fuensanta Gómez López, Amparo Massotti Littel (Solfeo) y José Luis López García (Guitarra y Conjunto Coral e Instrumental).

No era la primera vez que algunos de ellos acudían a la ciudad. Por intercesión de la Asociación y la Delegación Provincial de Educación, durante el curso académico de 1978/79, cien alumnos almerienses matriculados en enseñanza libre del Grado Elemental en el Conservatorio de la capital del Segura tuvieron la oportunidad de examinarse en la Escuela de Artes y la Escuela de Danza "Amelia del Águila" - calle San Leonardo, 3- ante los tribunales que integraron García Escobar, Baró, Espinosa, López García junto a Dulce Conejero Fernández o Josefa Guaita Sánchez, en Música; y María del Carmen Rubio Segado, Pedro Tortosa Fernández e Isabel de Ibarra Pérez para las aspirantes de Danza ${ }^{62}$.

Los murcianos impartieron enseñanza quincenal validándola con exámenes. En alternancia paralela principió una Academia de Música compuesta de docentes asentados en Almería que reunió a María del Carmen Oyonarte, María del Mar Batlles, Esperanza León Marín, Ana García Martínez, Manuel López, Juan Vicente García, Matilde Rodríguez y María de las Nieves Rodríguez ${ }^{63}$ bajo la dirección del profesor Leopoldo Pérez Torrecillas.

Se abrió un plazo de matriculación entre los días 18 al 22 de febrero de 1980. Gestionaron un local donde ubicar las clases, inicialmente asentido, pero finalmente no consentido como anteproyecto de Casa de la Música donde ensayaba la Banda Municipal en la Plaza de Bendicho, y adquirieron pianos y material didáctico. El Ayuntamiento, la Diputación y el Monte de Piedad y Caja de Ahorros de Almería afrontaron los gastos. Con memorable estrechez y eufórica aceptación social, el 27 de febrero acogió por vez primera al

\footnotetext{
${ }^{56}$ Entrevista personal a D. José Ramos Santander, Almería, 22 de mayo de 2018.

${ }^{57}$ Boletín Oficial del Estado (BOE) no 293, 8 de diciembre de 1977, p. 26.962.

${ }_{58}$ Ciento doce millones para centros escolares. 40.000 nuevos puestos escolares construidos en la provincia en 5 años. La Voz de Almería, 3 de febrero de 1983, p. 8; Almería se lleva el porcentaje más alto nacional de inversiones de educación por habitante. Ideal, 30 de abril de 1981.

59 La entrevista del día. Cerca de 253 millones para 3 nuevos colegios de EGB y dos institutos de Almería. La Voz de Almería, 1 de junio de 1978, p. 13.

60 Puede ser una realidad el Conservatorio. La Voz de Almería, 3 de mayo de 1978, pp. 12-13.

${ }^{61}$ Educación y Ciencia. Los exámenes para alumnos libres del Conservatorio de Música de Murcia, en junio y septiembre, se realizarán en Almería. Ideal, 1 de junio de 1979, p. 15; Educación y Ciencia. Ideal, 14 de junio de 1979 , p. 19.

${ }^{62}$ Archivo personal de D. Juan Rigaud Felices. Almería, 21 y 22 de junio de 1979.

${ }^{63}$ El Conservatorio de Música de Almería, una realidad. La Voz de Almería, 16 de febrero de 1980, p. 11.
} 


\section{CARMEN RAMÍREZ RODRÍGUEZ}

alumnado de preparatorio y primero de solfeo ${ }^{64}$ en el número 6 de la calle Valero Rivera, planta segunda del Edificio Concordia 2. Conjuntamente ofertaron a los 375 alumnos matriculados, las especialidades de Piano, Conjunto Coral, Guitarra y, a partir de mayo, Danza, en la calle Navarro Rodrigo, 27 (Marín, 1980, p. 11).

"Es deber -consigna el acta del 5 de noviembre de 1980 del Ayuntamiento- reconocer y exaltar la labor desarrollada por esta Asociación que, de alguna manera, está supliendo responsabilidades e iniciativas de la Administración con un comportamiento ejemplar de responsabilidad ciudadana, espíritu solidario e inquietud cultural”' ${ }^{\prime 5}$. En consecuencia, aquel año le fue concedido el Premio popular Odeón en la especialidad de Música ${ }^{66}$.

\subsection{CONSORCIO PARA Un CONSERVATORIO DE Música y DANZA DE Almería ${ }^{67}$}

La ampliación de la especialidad instrumental de violín y el incremento de matriculación a 756 inscripciones oficiales y 250 libres ${ }^{68}$ urgió en febrero de $1981^{69}$ el traspaso al inmueble de la Delegación Provincial de la Administración Institucional de Servicios Socio-Profesionales (AISS), en el número 14 de la calle Javier Sanz, por cesión del local de la Delegación de Trabajo.

El alcalde, Santiago Martínez Cabrejas, y el presidente de la Diputación Provincial, José Fernández Revueltas, acogieron el proyecto de la Asociación con interés y recelo al mismo tiempo por la disparidad y desmedida dilación presupuestaria que había acarreado el Consorcio para los Estudios Universitarios en Almería (Granados, 1980, p. 19). Con todo, el 24 de abril de 1981 ratificaron los estatutos del Consorcio para un conservatorio de Música y Danza de Almería por consecuencia de los acuerdos adoptados en los Plenos de ambas corporaciones, el $28^{70}$ y 5 de noviembre de $1980^{71}$, respectivamente.

${ }^{64}$ Conservatorio de Música de Almería. La Voz de Almería, 15 de febrero de 1980, p. 2.

65 AMA. Libro de actas no 29 (349), ff. 55v-57.

${ }^{66}$ Fallados los Premios populares Odeón, Almería. Ideal, 12 de noviembre de 1980, p. 2.

${ }^{67}$ ADPA. Acta de la sesión plenaria de 24 de abril de 1981, ff. 85v-90v. Recoge los Estatutos del Consorcio para la formación del Conservatorio de Música y Danza.

${ }_{68} \mathrm{Al}$ final posiblemente habrá conservatorio. La Voz de Almería, 6 de junio de 1981, pp. 16-17.

${ }^{69}$ Apuntes personales de D. Juan Rigaud Felices, Almería, sf.

70 ADPA. Acta de la sesión plenaria de 28 de noviembre de 1980, ff. 230-231.

${ }^{71}$ AMA. Libro de actas no 29 (349), ff. 55v-57. 


\begin{tabular}{|c|c|c|}
\hline \multicolumn{3}{|c|}{ CONSORCIO PARA UN CONSERVATORIO DE MÚSICA Y DANZA DE ALMERÍA } \\
\hline DESIGNIOS & \multicolumn{2}{|c|}{$\begin{array}{l}\text { Promover la creación del Conservatorio Superior de Música y Danza de Almería. } \\
\text { Sostener y subvencionar su funcionamiento durante tres años a partir de la aprobación de estos Estatutos por el } \\
\text { Ministerio de Educación y Universidades. } \\
\text { Elaborar el Reglamento de Régimen Interno. } \\
\text { Participar con los Órganos Rectores en el desarrollo de los estudios. }\end{array}$} \\
\hline & COMPOSICIÓN & $\begin{array}{l}\text { Presidente: Diputación Provincial } \\
\text { Vicepresidente: Alcalde } \\
\text { Seis vocales: tres diputados provinciales y tres concejales del Ayuntamiento de Almería. } \\
\text { Secretario: Secretario del Consorcio y el de la Comisión Informativa Municipal de } \\
\text { Cultura y Enseñanza. } \\
\text { Intervención: Empleado de la Diputación. } \\
\text { Depositaría: Empleado de la Diputación. }\end{array}$ \\
\hline $\begin{array}{l}\text { JUNTA } \\
\text { DE } \\
\text { GOBIERNO }\end{array}$ & ATRIBUCIONES & $\begin{array}{l}\text { Regir las actividades. } \\
\text { Las propuestas de modificación o disolución del Consorcio. } \\
\text { El ejercicio de toda clase de acciones. } \\
\text { La adquisición y disposición de bienes y derechos, transmisiones sobre ellos y cesión de } \\
\text { quitas y esperas. } \\
\text { La aprobación de presupuestos ordinarios y extraordinarios, contratación de } \\
\text { empréstitos, censura de cuentas, reconocimientos de créditos y otros compromisos } \\
\text { económicos. } \\
\text { La contratación de obras públicas y servicios. } \\
\text { La aprobación de tarifas aplicables por la prestación de servicios. } \\
\text { El nombramiento, premio y corrección de los funcionarios y la contratación del } \\
\text { personal. } \\
\text { La inscripción en el Registro de la Propiedad de los bienes inmuebles y derechos reales. } \\
\text { Aquellas otras que, atendida la finalidad del Consorcio, se establezcan por precepto } \\
\text { legal. }\end{array}$ \\
\hline $\begin{array}{l}\text { RÉGIMEN } \\
\text { JURÍDICO }\end{array}$ & $\begin{array}{l}\text { Celebración de sesi } \\
\text { Acuerdos por may } \\
\text { conformidad en los } \\
\text { - Admisió1 } \\
\text { - Alteració } \\
\text { - Enajena } \\
\text { presupues } \\
\text { - Concesió } \\
\text { - Contrata } \\
\text { - Destituci } \\
\text { - Disolucic }\end{array}$ & $\begin{array}{l}\text { rdinaria trimestral sin perjuicio de las extraordinarias. } \\
\text { favorable. Voto favorable de los dos tercios y de la mayoría absoluta para otorgar } \\
\text { erdos de las siguientes materias: } \\
\text { nuevos miembros } \\
\text { l nombre y modificación de los Estatutos del Consorcio. } \\
\text { y adquisición de bienes inmuebles siempre que excediese del } 15 \% \text { del importe del } \\
\text { ingresos del Consorcio. } \\
\text { arrendamiento de bienes y servicios. } \\
\text { de préstamos y concesión de quitas y esperas. } \\
\text { le funcionarios. } \\
\text { el Consorcio. }\end{array}$ \\
\hline $\begin{array}{l}\text { RÉGIMEN } \\
\text { ECONÓMICO }\end{array}$ & $\begin{array}{l}\text { Aprobación de los } \\
\text { Contratación de em } \\
\text { Adquisición y dispo } \\
\text { Exacción de derech } \\
\text { Subvenciones, dona }\end{array}$ & $\begin{array}{l}\text { apuestos ordinarios y extraordinarios. } \\
\text { titos. } \\
\text { tasas. } \\
\text { s, legados y auxilios a favor del Consorcio. }\end{array}$ \\
\hline DISOLUCIÓN & $\begin{array}{l}\text { Terminación del pla } \\
\text { Desaparición del Cc } \\
\text { Imposibilidad legal } \\
\text { Por acuerdo de la Ju }\end{array}$ & $\begin{array}{l}\text { le duración estipulado de tres años. } \\
\text { rvatorio de Música y Danza de Almería. } \\
\text { aterial de cumplir sus fines. } \\
\text { de Gobierno con el quórum advertido en el apartado del régimen jurídico. }\end{array}$ \\
\hline
\end{tabular}

Tabla 5: Consorcio para un conservatorio de música y danza de Almería. Fuente: Elaboración propia a partir de las fuentes documentales consultadas.

El Consejo Permanente de la Presidencia de la Junta de Andalucía, en reunión celebrada el 8 de febrero de 1982, los refrendó ${ }^{72}$. El programa enviado al Ministerio de Educación y Ciencia fue el que manejaba el Conservatorio Superior de Murcia con el objeto de ofrecer continuidad formativa a los matriculados ${ }^{73}$. Atendiendo a la petición formulada

72 ADPA. Acta de la sesión del 30 de abril de 1982, ff. 258-258v.

${ }^{73}$ Carta de D. Juan Rigaud Felices a D. Manuel Massotti. Almería, 29 de agosto de 1981. 
por el Consorcio, de conformidad con el dictamen favorable del Consejo Nacional de Educación y a propuesta del Ministro de Educación y Ciencia, José María Maravall Herrero, el 19 de enero de 1983, el Consejo de Ministros reconoció validez académica oficial a las enseñanzas de Grado Elemental del Conservatorio de Música no estatal de Almería ${ }^{74}$. La Orden de 10 de noviembre de 1986 concedió la enseñanza elemental de Danza Española y Danza Clásica con efectos retroactivos a la transferencia de competencias a la Comunidad autónoma de Andalucía ${ }^{75}$.

\section{ORganización ESCOLAR DEL CONSERVATORIO (1982-1987)}

Las aulas eran insuficientes y, el 1 de febrero de 1983, el noticiero comunica la traslación al número 22 de la rambla del Obispo Orberá, junto al Mercado central. Sin embargo, el curso académico de 1983/1984 comenzó el 19 de diciembre de 1983, por obras de acondicionamiento del primer piso $^{76}$, barajándose un futuro domicilio en el Casino o la cesión municipal de un terreno en la Avenida del Mediterráneo.

A los cuatro cursos de las enseñanzas de Solfeo y Teoría de la Música, así como de las especialidades instrumentales (Piano, Guitarra y Violín), precedió un curso preparatorio de carácter voluntario. Admitió matriculación oficial y libre del alumnado con exámenes de fin de curso en las convocatorias independientes de junio y septiembre. Las pruebas se realizaban con tribunal compuesto por tres miembros designados por el director del conservatorio. A los alumnos oficiales les podía ser concedido sin examen, aprobado por puntuación académica del curso siempre que superasen la calificación de 5 y se tratase de cursos diferentes al último de la asignatura o del grado.

A la vista de los datos, podemos deducir que los estudios cursados en el centro no supusieron una opción con expectativas profesionales sino una formación complementaria. El porcentaje de aspirantes que concluía las Enseñanzas Elementales -entre un 0'5 y un 0'9fue exiguo y desproporcionado al conjunto de matriculaciones anuales, favoreciendo la masificación en las aulas.

\begin{tabular}{|c|c|c|c|}
\hline CURSO & ALUMNOS & ALUMNAS & TOTAL \\
\hline $1982-1983$ & & 10 & 10 \\
\hline $1983-1984$ & 2 & 14 & 16 \\
\hline $1984-1985^{77}$ & & & \\
\hline $1985-1986$ & 6 & 9 & 15 \\
\hline $1986-1987$ & 10 & 9 & 19 \\
\hline
\end{tabular}

Tabla 6. Alumnado que concluyó el Grado Elemental. Cursos 1982/1983-1986/1987. Fuente: Elaboración propia a partir de los datos del Instituto Nacional de Estadística. Estadística de la Enseñanza en España. Cursos 1982/1983-1986/1987.

\footnotetext{
${ }^{74} \mathrm{BOE} \mathrm{n}^{\circ} 43,19$ de febrero de 1983, p. 4.785.

75 BOJA n ${ }^{\circ} 108,5$ de diciembre de 1986, pp. 3.765-3.766 y BOE n ${ }^{\circ} 19,22$ de enero de 1983, pp. 1.663-1.664.

El conservatorio, reconocido oficialmente. La Voz de Almería, 23 de febrero de 1983, pp. 1 y 3.

${ }^{76}$ Obras en el Conservatorio. La Voz de Almería, 15 de diciembre de 1983, p. 3.

${ }^{77} \mathrm{Se}$ desconoce el número de alumnos que terminaron el Grado Elemental en ese curso.
} 
De hecho, la diversidad de opiniones en torno a exámenes con tribunales o a una evaluación continuada ocupó el tema central de la asamblea de la Asociación de Padres, celebrada el 25 de febrero de 1985. La mayoría de los asistentes votó a favor de la segunda disyuntiva (Félix Almarza, 1985, p. 20).

El número de docentes fluctuó entre los 14 y 18 con un perceptible predominio de profesoras. Tres de ellas amaestraron Danza en las especialidades de Danza española y Ballet clásico. Los restantes impartieron y compartieron, en algunos casos, las asignaturas y especialidades instrumentales de Solfeo y Teoría de la Música y Conjunto Coral e Instrumental con Guitarra, Piano y Violín ${ }^{78}$.

\begin{tabular}{|c|c|c|c|}
\hline CURSO & PROFESORES & PROFESORAS & TOTAL \\
\hline $\mathbf{1 9 8 2 - 1 9 8 3}$ & 4 & 10 & 14 \\
\hline $\mathbf{1 9 8 3 - 1 9 8 4}$ & 5 & 11 & 16 \\
\hline $\mathbf{1 9 8 4 - 1 9 8 5}$ & 6 & 12 & 18 \\
\hline $\mathbf{1 9 8 5 - 1 9 8 6}$ & 6 & 9 & 15 \\
\hline $\mathbf{1 9 8 6 - 1 9 8 7}$ & 6 & 9 & 15 \\
\hline
\end{tabular}

Tabla: 7. Profesorado cursos 1982/1983-1986/1987.

Fuente: Elaboración propia a partir de los datos del Instituto Nacional de Estadística. Estadística de la Enseñanza en España. Cursos 1982/1983-1986/1987.

Apreciamos una superioridad porcentual numérica de alumnado de música: entre un $81,30 \%$ y $86,26 \%$ frente a un $13,73 \%$ y $18,69 \%$ de danza; inexistencia de alumnos en Ballet clásico y preponderancia de alumnas que cursan la especialización española. Inferioridad aritmética también de alumnos en música ante el de discípulas. Supremacía de matriculación oficial sobre la libre con un incremento de la última entre los cursos de 1985/1986 y 1986/1987.

\begin{tabular}{|c|c|c|c|c|c|c|c|}
\hline \multicolumn{8}{|c|}{ MÚSICA } \\
\hline \multirow[t]{2}{*}{ CURSOS } & \multicolumn{3}{|c|}{ ALUMNOS } & \multicolumn{3}{|c|}{ ALUMNAS } & \multirow[t]{2}{*}{ TOTAI } \\
\hline & Oficiales & Libres & Total & Oficiales & Libres & Total & \\
\hline $1982-1983$ & 412 & 74 & 486 & 1.039 & 175 & 1.214 & 1.700 \\
\hline 1983-1984 & 523 & 72 & 595 & 1.160 & 165 & 1.325 & 1.920 \\
\hline 1984-1985 & 578 & 107 & 685 & 1.170 & 133 & 1.303 & 1.988 \\
\hline $1985-1986$ & 363 & 185 & 548 & 746 & 283 & 1.029 & 1.577 \\
\hline 1986-1987 & 380 & 177 & 557 & 733 & 328 & 1.061 & 1.618 \\
\hline
\end{tabular}

Tabla 8: Matrícula total de alumnado. Cursos 1982/1983-1986/1987.

Fuente: Elaboración propia a partir de los datos del Instituto Nacional de Estadística.

Estadística de la Enseñanza en España. Cursos 1982/1983-1986/1987.

\footnotetext{
78 Véase al respecto, Apéndice no 1. Tabla 10: Recursos Humanos del Conservatorio (1982-1987).
} 
CARMEN RAMÍREZ RODRÍGUEZ

\begin{tabular}{|c|c|c|c|c|c|c|}
\hline \multicolumn{9}{|c|}{ DANZA } \\
\hline \multirow{2}{*}{ TOTAL } & \multirow{2}{*}{ CURSOS } & \multicolumn{3}{|c|}{ DANZA ESPAÑOLA } & \multicolumn{2}{c|}{ BALLET CLÁSICO } \\
\cline { 3 - 7 } & & ALUMNOS & ALUMNAS & TOTAL & ALUMNAS & TOTAL \\
\hline $\mathbf{2 5 1}$ & $\mathbf{1 9 8 5 / 8 6}$ & 4 & 216 & 220 & 31 & 31 \\
\hline $\mathbf{3 7 2}$ & $\mathbf{1 9 8 6 / 8 7}$ & 7 & 292 & 299 & 73 & 73 \\
\hline
\end{tabular}

Tabla 9: Matrícula total de alumnado. Cursos 1982/1983-1986/1987.

Fuente: Elaboración propia a partir de los datos del Instituto Nacional de Estadística.

Estadística de la Enseñanza en España. Cursos 1982/1983-1986/1987.

La actividad extraescolar corrió paralela a la académica. Coincidiendo con la conmemoración del Año Europeo de la Música, el profesor de guitarra, Jaime Rodríguez Torronteras, inició el 25 de enero de 1985 un ciclo de conciertos organizado por el conservatorio en colaboración con el centro asociado de la Universidad Nacional de Educación a Distancia (UNED) que tuvo lugar en el Aula de Cultura de la Caja de Ahorros con el deseo de promocionar intérpretes y acercar la música a los educandos a través de sus audiciones. Más tarde, la Asociación Filarmónica y el Colegio Universitario la secundaron ${ }^{79}$.

En reunión celebrada el 12 de junio de 1986, la Junta de Gobierno del Consorcio acordó modificar los estatutos prorrogando automáticamente la participación y aportación de las entidades ${ }^{80}$.

\section{ConClusiones}

$\mathrm{Al}$ acontecer los 80, la creación de conservatorios elementales estatales y no estatales, así como de centros no oficiales reconocidos y autorizados prolifera en las publicaciones del Boletín Oficial del Estado de España y sus diferentes comunidades autónomas. Algunos centros elementales pasaron a ser profesionales y adquirieron la categoría de superiores otros simultáneamente.

Con 130.000 habitantes, Almería relegaba los vestigios de la horizontalidad urbana de su arquitectura y perfilaba un nuevo paisaje vertical por causa del crecimiento incontrolado de la ciudad sureña con una consiguiente multiplicación de la red de puestos escolares e infraestructuras educativas entre 1978 y 1983. Entretanto, el Conservatorio de Música y Danza -análogo a otros peninsulares e insulares (Pérez Gutiérrez, 1993, pp. 17-48)- emergía de una academia de música subvencionada por la Diputación y el Ayuntamiento que impulsó la Asociación de Padres de alumnos y Amigos pro-conservatorio de Música de Almería.

Aunque a partir del 14 de marzo de 1952, en virtud de un Decreto publicado por el Ministerio de Educación Nacional, se efectuó la división de los antiguos Conservatorios de Música y Declamación integrándose los estudios de declamación y baile como secciones de las Escuelas de Arte Dramático; Música y Danza emanaron juntas en 1980 y subordinadas a la validación del Conservatorio Superior de Murcia hasta la terminación del curso académico de 1981/1982. El 19 de febrero de 1983 se convirtió en el octavo centro docente andaluz al

\footnotetext{
${ }^{79}$ Véase al respecto, Apéndices II. Tabla 11: Actividades culturales y musicales.

80 AMA, Comisión Informativa Municipal de Cultura y Enseñanza. Certificado del secretario del Consorcio para el Conservatorio de Música y Danza. Almería, 13 de junio de 1986.
} 
que se le concedió competencia oficial académica para cursar estudios tras los casos de Córdoba (1922), Málaga (1926), Cádiz (1929 y 1960), Sevilla (1933), Granada (1948) ${ }^{81}$, Jaén (1958) y Jerez de la Frontera $(1964)^{82}$. Paralelo a Linares, Huelva lo consiguió en $1986^{83}$. Tanto los antecesores autonómicos, el de Valencia (1911) (Fontestad Piles, 2006, pp. 448-449) como los vecinos de Murcia (1918) (Encabo Fernández, 2017, pp. 557) y Cartagena (1928) provenían de Sociedades Económicas de Amigos del País, liceos, academias y escuelas de arraigo decimonónico. La limitada capacidad para emprender empresas colectivas perdurables en Almería causó su retardo ${ }^{84}$.

Los estatutos de la Asociación y los del Consorcio refieren al centro bajo la denominación de «Conservatorio de Música y Danza» y así la hemos mantenido al titular este trabajo. De hecho, las memorias del Instituto Nacional de Estadística, entre los cursos 1982/1983 y 1984/1985, no delimitan al profesorado y matriculación de una y otra al numerarlo. A partir del curso 1985/1986 se desglosan a raíz de la Orden de 10 de noviembre de 1986 que autorizó las especialidades de Danza Clásica y Danza Española de Grado Elemental en el centro.

En el artículo primero de los Estatutos del Consorcio y las bases del concurso de ideas para su construcción (y, por ende, del proyecto seleccionado), el conservatorio figura bajo la errónea calificación de Superior, subsanada por el Delegado provincial de Educación, Vicente Abad Montoya. Los respectivos Decretos 8 y 9/1988, de 20 de enero, establecieron la Escuela de Arte Dramático y Danza (Sección Danza) ${ }^{85}$-integrada en 1994 al Conservatorio Profesional de Danza ${ }^{86}$ y el Conservatorio Profesional de Música de Almería, dependientes de la Consejería de Educación y Ciencia de la Junta de Andalucía, desde el 1 de septiembre de 1987.

A lo largo de estos años han ocupado una misma sede en cuatro paraderos diferentes a la espera de su definitiva escisión a través de la futura cimentación del Conservatorio Profesional de Danza "Kina Jiménez" cuya licitación ha incluido el Plan de Inversiones en Infraestructuras Educativas 2017/2018 y de la anhelada culminación de la segunda etapa

\footnotetext{
${ }^{81}$ En los últimos años han sido varios los investigadores que han estudiado la creación de los conservatorios en nuestro país. Sobre estos centros andaluces, hemos consultado: Flores Núñez, 2016, p. 118; Cámara Martínez, 2011, pp. 222, 301-303, 307-308; González de Herrera Carrillo, 2000, p. 242; Navarro Mota \& Pemán, 1976, pp. 59-60, 65.

82Sobre la creación del Conservatorio de Jaén, véase https://www.dipujaen.es/archivo/datosfondos/conservatorio-musica-andres/historia_institucional.html [consultado el 26 de agosto de 2019] y Decreto $1463 / 1964 \ldots$

${ }^{83}$ BOJA n ${ }^{\circ} 92,7$ de octubre de 1986, p. 3.156.

${ }^{84}$ Aunque la Sociedad Económica de Amigos del País de Almería se constituyó en 1834 (Archivo Histórico Provincial de Almería, legajo 4401-1), paradójico a otras de su idiosincrasia, fue una institución de biografía intermitente, desprovista de vitalidad y actividad a la hora de divulgar el conocimiento de las artes y las ciencias. El Liceo contribuyó a formar desde 1843 a 1875 la afición filarmónica de la naciente burguesía a través de repertorios pianísticos y operísticos de vocalidad italiana exhibidos en las sesiones de competencia. Cf. Ramírez Rodríguez, 2018, p. 63.

${ }^{85}$ BOJA n $^{\circ}$ 9, 5 de febrero de 1988, p. 405.

${ }^{86}$ BOJA no 150, 24 de noviembre de 1994, pp. 11.315-11.316.

${ }^{87}$ BOJA n $n^{\circ} 154,7$ de agosto de 2012, p. 42.
} 


\section{CARMEN RAMÍREZ RODRÍGUEZ}

edificatoria del proyecto de 1985 que incluye el levantamiento de su auditorio y una plaza pública.

Decisiva (pero escasamente valorada y desatendida al presente) fue la actividad de la Asociación en su triple función promotora, pedagógica y colaboradora con el Ayuntamiento, la Diputación, Monte de Piedad y Caja de Ahorros de Almería, la Tertulia Indaliana, el Centro Asociado de la Universidad Nacional de Educación a Distancia, la Asociación Filarmónica de Almería y el Colegio Universitario en su afán constante por aproximar la música a la ciudadanía. Sirva este artículo de agradecimiento a su buen hacer y contribuya a ofrecer una visión global de la educación musical española, de los diferentes planes de estudio de los conservatorios y la aplicación de sus grados, pendiente de futuras investigaciones sobre la evolución de sus enseñanzas en la provincia de Almería bajo la administración autonómica.

\section{APÉNDICES}

I. RECURSOS HUMANOS DEL CONSERVATORIO (1982-1987)

\begin{tabular}{|c|c|c|}
\hline ESPECIALIDAD & PROFESORADO AUXILIAR & $\begin{array}{c}\text { PERSONAL DE } \\
\text { ADMINISTRACIÓN }\end{array}$ \\
\hline $\begin{array}{c}\text { SOLFEO } \\
\text { Y } \\
\text { TEORÍA DE LA MÚSICA }\end{array}$ & $\begin{array}{l}\text { Juan Ramón Balmón Cruz } \\
\text { Manuel Miguel López Martínez } \\
\text { María del Carmen Oyonarte Gómez } \\
\text { María de las Nieves Rodríguez Mellado } \\
\text { María Isabel Fernández Ortega } \\
\text { Milagros Dueñas Redondo } \\
\text { Pedro Sánchez Martínez } \\
\text { Víctor Félix de la Cruz López }\end{array}$ & María del Carmen Soler Rodríguez \\
\hline PIANO & $\begin{array}{l}\text { Inmaculada Contreras Naranjo } \\
\text { José María Martínez-Oña López } \\
\text { (Director, 1985-87) } \\
\text { Juan Javier Herreros Díaz } \\
\text { Leopoldo Pérez Torrecillas } \\
\text { (Director, 1982-85) } \\
\text { María del Carmen Jurado Zambrano } \\
\text { María del Mar Batlles Campos } \\
\text { Milagros Gutiérrez Irles } \\
\text { Ramona Herrero Jiménez }\end{array}$ & \\
\hline GUITARRA & $\begin{array}{l}\text { Jaime Rodríguez Torronteras } \\
\text { Juan Vicente García García } \\
\text { Matilde Rodríguez Expósito }\end{array}$ & \\
\hline VIOLÍN & $\begin{array}{l}\text { Justo María Andújar Peral } \\
\text { Rosalía Gutiérrez Irles }\end{array}$ & \\
\hline DANZA & $\begin{array}{l}\text { Joaquina Jiménez Sánchez } \\
\text { Paloma Peiró Navarrete } \\
\text { Rosa María Nicolás Moreno }\end{array}$ & \\
\hline
\end{tabular}

Tabla 10: Recursos humanos del conservatorio (1982-1987). Fuente: Elaboración propia a partir de los datos del ADPA, Consorcio para el Conservatorio de Música y Danza. Carpeta 631, Almería, 14 de octubre de 1981; Caja 634. 31 de enero de 1985, 1 de mayo de 1985; Caja 636. Almería, 30 de enero de 1987, 27 de febrero de 1987, 31 de marzo de 1987. 
ANTECEDENTES, CREACIÓN Y ORGANIZACIÓN ESCOLAR DEL

CONSERVATORIO DE MÚsiCa y DANZA No ESTATAL dE AlMERÍA (1982-1987)

\section{ACTIVIDADES CULTURALES Y MUSICALES}

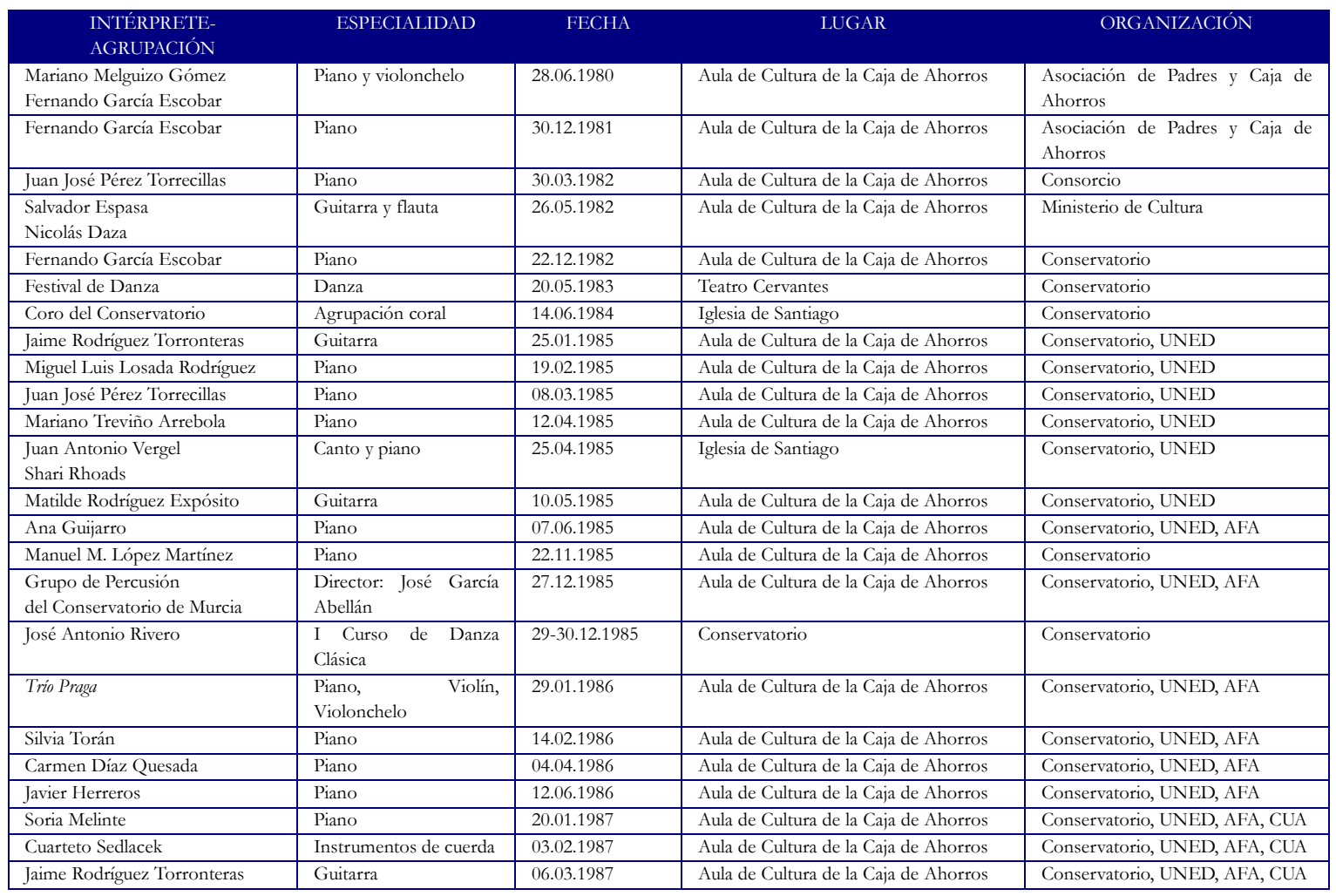

Tabla 11: Actividades culturales y musicales. Fuente: Elaboración propia a partir de la hemerografía consultada. 


\section{CARMEN RAMÍREZ RODRÍGUEZ}

\section{BIBLIOGRAFÍA}

Anónimo (1915). Memoria de la Academia de Bellas Artes. Curso 1913/14. Almería: Tipografía El siglo XX.

Blanco Martín, M. A. (2015). Cultura, periodismo y transición democrática en Almería (1973-1986). (Tesis doctoral). Almería: Universidad de Almería.

Bocero García, A. (2009). Creación y trayectoria del Grupo Indaliano. Almería: Arráez editores.

Cámara Martínez, R. (2011). El real conservatorio de música y declamación "Victoria Eugenia” de Granada: organización de la institución y desarrollo del currículo (1921-1952). (Tesis doctoral). Granada: Universidad de Granada. Recuperado de https://digibug.ugr.es/handle/10481/19067

Casero García, E. (2000). La España que bailó con Franco: Coros y Danzas de la Sección Femenina. Madrid: Nuevas Estructuras.

Castañón Rodríguez, M. R. (2012). El profesorado de educación musical durante el franquismo. Revista electrónica interuniversitaria de formación del profesorado, XII, 4, pp. 97 107.

Consueta de la Santa Iglesia Catedral de la ciudad de Almería que deben observar el Ilustrísimo Señor Deán y Cabildo de ella y todos los demás Ministros (1577). Reimpresa de orden de dicho Ilustrísimo Cabildo con licencia en Granada: herederos de don Joseph de la Puerta, 1761.

Encabo Fernández, E. (2017). Murcia, Vergel de artistas: la fundación del conservatorio y el renacimiento cultural de la ciudad. Revista de Musicología, XL, 2, pp. 543-564.

Escámez Mañas, F. J. (2015). Los Canónigos del Cabildo de la Catedral de Almería (1505-1936). (Tesis doctoral). Sevilla: Universidad de Sevilla).

Flores Núñez, M. P. (2016). Conservatorio de Música de Málaga. Proceso pedagógico, Historia y género (1869-1959). (Tesis doctoral). Málaga: Universidad de Málaga. Recuperado de https://riuma.uma. es/xmlui/handle/10630/11547

Fontestad Piles, A. (2006). El Conservatorio de Música de Valencia. Antecedentes, fundación y primera etapa (1879-1910). Valencia: Universitat, Servei de Publications.

Gómez Díaz, D. (2001). El oficio de contable. Historia de la educación y profesión en Almería (1784-1941). Historia de la educación. Revista interuniversitaria, XX, pp. 237-259. 
ANTECEDENTES, CREACIÓN Y ORGANIZACIÓN ESCOLAR DEL

CONSERVATORIo de Música Y DanZa No ESTATAL de ALMERÍa (1982-1987)

González de Herrera Carrillo, J. (2000). La fundación del conservatorio de música de Sevilla y su difusión en el periódico $A B C$ durante la II República. Sevilla: Educación y medios de comunicación social.

López Marinas, J. M. (2009). La Asociación de Cultura Musical. Papeles del Festival de Música de Cádiz, IV, pp. 291-319.

López Martín, J., Bonillo Navarro, C. y Requena García, A. (1997). Noticias y catálogo de música en el archivo de la S. y A.I.C. de Almería. Granada: Centro de Documentación Musical de Andalucía, p. 156.

Navarro Mota, D., Pemán, J. M. (1976). La historia del Conservatorio de Cádiz en sus documentos. Cádiz: Instituto de Estudios Gaditanos.

Pérez Gutiérrez, M. (1993). Los conservatorios españoles. Historia, reglamentaciones, planes de estudio, centros, profesorado y alumnado. Música y Educación, XV, pp. 17-48.

Ramírez Rodríguez, C. (2018). Alicia O’Connor (ca. 1828-1871) y sus aportaciones a la canción lírica con piano. Revista de Musicología, XLI, 1, pp. 57-97.

Rodríguez López, S. (2005). La Sección Femenina y la sociedad almeriense durante el franquismo: de las mujeres del movimiento al movimiento democrático de mujeres. (Tesis doctoral). Almería: Universidad de Almería, Servicio de Publicaciones.

Ruiz-Larrea Cangas, C. (1986). Conservatorio de música, Almería. El Croquis, 26, pp. 80-83.

Ruiz-Larrea Cangas, C. (1989). Conservatorio Superior de Música. Almería, AQ, 5, p. 41.

Salvador Estrella, F. (1915). Memoria de la Academia de Bellas Artes. Curso de 1912 a 1913. Almería: Tipografía de La Información.

Sánchez Cañadas, A. (2004). La Escuela de Artes de Almería en la transición de los siglos XIX y XX. Almería: Instituto de Estudios Almerienses.

Segura Del Pino, D. (2016). La virgen de Montserrat. Patrona de la vega de Almería, María, Regina Naturae. En V. Sánchez Ramos (Coord.). Congreso Mariano Nacional sobre advocaciones de la Virgen vinculadas a la naturaleza: Historia, arte y cultura, pp. 105-108. Berja, Almería: Centro Virgitano de Estudios Históricos. 


\section{CARMEN RAMÍREZ RODRÍGUEZ}

\section{HEMEROGRAFÍA}

Academia. La Crónica Meridional, 27 de marzo de 1902, p. 2.

Acién Lirola, M. (1988). César Ruiz Larrea y Antonio Góngora Sebastián recibieron el Premio "Arco" de Arquitectura por el Conservatorio Superior de Música, Ideal, 24 de abril, p. 7.

A las ocho, en la Caja de Ahorros. La Voz de Almería, 25 de enero de 1985 p. 4.

Al final posiblemente habrá conservatorio. La Voz de Almería, 6 de junio de 1981, pp. 16-17.

Almería escenificará la estampa Virgen del Mar en la Romería Andaluza. La Voz de Almería, 28 de abril de 1973, p. 3.

Almería se lleva el porcentaje más alto nacional de inversiones de educación por habitante. Ideal, 30 de abril de 1981.

Almería y la Universidad. La Voz de Almería, 13 de octubre de 1971, p. 2.

Arpe, C. J. de. (1908). La vida en Almería. El Heraldo de Madrid, 13 de diciembre, p. 4.

Artistas para el mañana. Ideal, Almería, 20 de junio de 1974, p. 9.

Ciento doce millones para centros escolares. 40 mil nuevos puestos escolares construidos en la provincia en 5 años. La Voz de Almería, 3 de febrero de 1983, p. 8.

Concierto de presentación de la Agrupación de Guitarras de la Obra Sindical Educación y Descanso "Manuel de Falla". La Voz de Almería, 23 de agosto de 1973, p. 2.

Conservatorio de Música de Almería. La Voz de Almería, 15 de febrero de 1980, p. 2.

Diario de Almería, 4 de febrero de 1917, p. 1.

El Día (Almería), 28 de octubre de 1916, p. 4.

Educación y Ciencia. Los exámenes para alumnos libres del Conservatorio de Música de Murcia, en junio y septiembre, se realizarán en Almería, Almería. Ideal, 1 de junio de 1979, p. 15.

Educación y Ciencia, Almería. Ideal, 14 de junio de 1979, p. 19.

El Conservatorio de Música de Almería, una realidad. La Voz de Almería, 16 de febrero de 1980, p. 11. 
ANTECEDENTES, CREACIÓN Y ORGANIZACIÓN ESCOLAR DEL

Conservatorio de Música y Danza no ESTATAl de Almería (1982-1987)

El conservatorio, reconocido oficialmente. La Voz de Almería, 23 de febrero de 1983, pp. 1 y 3.

El himno a Almería. El Día, 23 de julio de 1916, p. 1.

El maestro Barco. Necesitamos un conservatorio, Almería. Ideal, 1 de octubre de 1972, p. 7.

El quinteto municipal de la Biblioteca Villaespesa, Almería. Yugo, 4 de enero de 1951, p. 8.

En el Ayuntamiento. La Crónica Meridional, 17 de octubre de 1916, p. 2.

En la Academia de Bellas Artes. La Crónica Meridional, Almería, 8 de octubre de 1917, p. 2.

En la Catedral. La Independencia, 23 de enero de 1919, p. 2.

En la Catedral. La Independencia, 2 de noviembre de 1923, p. 2.

En la Catedral. La Independencia, 9 de diciembre de 1923, p. 1.

En la Catedral. La Independencia, 5 de abril de 1925, p. 1.

En la Catedral. Fiesta de todos los Santos. La Independencia, 2 de noviembre de 1927, p. 1.

En la Catedral. Domingo de Ramos. La Independencia, 01.04.1928, p. 1.

En la Catedral. La Inmaculada Concepción. La Independencia, 7 de diciembre de 1928, p. 4.

En el Cuartel. El acto de ayer. La Crónica Meridional, 7 de mayo de 1920, p. 4.

Enseñanza para la mujer. La Crónica Meridional, 23 de octubre de 1903, p. 2.

Exámenes. La Crónica Meridional, 25 de julio de 1918, p. 1.

Exámenes en la Academia de Bellas Artes. La Crónica Meridional, 7 de julio de 1925, p. 6.

Falange española tradicionalista y de las JONS. Yugo, Almería, 31 de julio de 1942, p. 6.

Fallados los Premios populares Odeón, Almería. Ideal, 12 de noviembre de 1980, p. 2.

Festival cinematográfico. La Crónica Meridional, 10 de enero de 1924, p. 2.

Félix Almarza, I. (1985). El tema de los exámenes con tribunales divide a la Asociación de Padres de Alumnos del Conservatorio. Ideal, 27 de febrero, p. 20.

Félix Almarza, I. (1986). En el curso 87-88 echará a andar el Conservatorio Profesional de Música, Ideal, 3 de enero, p. 8.

Festejos para hoy. El Defensor de Almería, 31 de agosto de 1916, p. 1. 


\section{CARMEN RAMÍREZ RODRÍGUEZ}

Festival de Danza del Conservatorio. La Voz de Almería, 18 de mayo de 1982, p. 4.

Festividad del Corpus. La Independencia, 11 de junio de 1925, p. 1.

Fiesta de la Purificación. La Independencia, 3 de febrero de 1928, p. 1.

Fiestas de Navidad. La Independencia, 25 de diciembre de 1923, p. 1.

Filarmónica almeriense. Heraldo de Almería, 18 de julio de 1934, p. 1.

García Verdejo, P. (1915). La Academia de Bellas Artes. El Popular, 23 de mayo, pp. 1 y 4.

Granados, J. M. (1981). Conservatorio para Almería. Ideal, 11 de noviembre, p. 19.

Himno a Almería. La Crónica Meridional, 1 de septiembre de 1916, p. 2

Historias almerienses. La Voz de Almería, 27 de febrero de 1977, p. 11.

Inminente inicio de las obras del nuevo Conservatorio Superior de Música. Almería, Ideal, 14 de julio de 1985, p. 18.

La Academia de Bellas Artes. La Independencia, 26 de junio de 1912, p. 2.

La Academia de Bellas Artes y el Ayuntamiento. Diario de Almería, 22 de mayo de 1924, p. 1.

La Alhambra, 306, 15 de diciembre de 1910, p. 12.

La Alhambra, 471, 15 de noviembre de 1917, p. 14.

La Banda del Hospicio. La Independencia, 16 de julio de 1919, p. 3.

La calle. La Voz de Almería, 6 de enero de 1978, p. 12.

La creación de un Conservatorio de música en Almería. Yugo, 26 de abril de 1953, pp. 1 y 6.

La enseñanza de la música en Almería. La Voz de Almería, 20 de marzo de 1971, p. 12.

La enseñanza en Almería. El Radical, 1 de octubre de 1907, p. 1.

La entrevista del día. La Voz de Almería, 1 de junio de 1978, p. 13.

La Escuela Oficial de Comercio. Diario de Almería, 5 de abril de 1935, p. 1.

La festividad de ayer. La Independencia, 9 de diciembre de 1927, p. 1.

La Filarmónica Almeriense. La Crónica Meridional, 13 de julio de 1934, p. 2.

La instalación de un conservatorio es algo de necesidad inmediata. Yugo, 23 de mayo de 1953, pp. 1 y 6.

La Voz de Almería, 25 de julio de 1974, p. 13. 
ANTECEDENTES, CREACIÓN Y ORGANIZACIÓN ESCOLAR DEL

CONSERVATORIo de Música Y DanZa No ESTATAL de ALMERÍa (1982-1987)

La Voz de Almería, 30 de marzo de 1982, p. 9.

La Voz de Almería, 18 de diciembre de 1982, p. 9.

La Voz de Almería, 25 de enero de 1985, p. 4.

La Voz de Almería, 13 abril de 1985, p. 6.

La Voz de Almería, 25 de abril de 1985, p. 25.

La Voz de Almería, 7 de junio de 1985, p. 8.

La Voz de Almería, 22 de diciembre de 1985, p. 12.

La Voz de Almería, 29 de diciembre de 1985, p. 4.

La Voz de Almería, 25 de enero de 1986, p. 4.

La Voz de Almería, 29 de enero de 1986, p. 28.

La Voz de Almería, 14 de febrero de 1986, p. 25.

La Voz de Almería, 4 de abril de 1986, p. 24.

Los grupos folklóricos de la región se preparan en Almería, Almería. Ideal, 10 de marzo de 1973, p. 11.

Marín, B. (1980). La tertulia indaliana del viernes. Juan Rigaud habló del Conservatorio de Música, La Voz.de Almería, 17 de febrero, p. 11.

Los presupuestos municipales. El Radical, Almería, 14 de noviembre de 1909, p. 1

Masegosa Requena, J. L. (1979). Escuela de Danza Amelia del Águila. La Voz. de Almería, 5 de julio, pp. 12-13.

Miserere de hoy. La Crónica Meridional, 23 de marzo de 1921, p. 1.

Necrología. Diario de Almería, 1 de enero de 1929, p. 1.

Noguera, E. (1916). Los centros culturales. En la Academia de Bellas Artes. El Día, 20 de octubre, p. 1.

Obras en el Conservatorio. La Voz. de Almería, 15 de diciembre de 1983, p. 3.

Oposiciones. La Crónica Meridional, Almería, 6 de abril de 1909, p. 2.

Puede ser una realidad el Conservatorio. La Voz de Almería, 3 de mayo de 1978, pp. 12-13.

Solemnidades religiosas. La Independencia, Almería, 17 de mayo de 1921, p. 1. 


\section{CARMEN RAMÍREZ RODRÍGUEZ}

Tertulia indaliana. La Voz de Almería, 23 de junio de 1971, pp. 2 y 11.

Viernes Santo. La Independencia, 9 de abril de 1925, p. 1.

Un concurso. La Independencia, Almería, 21 de enero de 1912, p. 1.

Un reconocimiento a la tradición musical y valores almerienses. La Voz de Almería, 24 de febrero de 1983, p. 9.

Una feliz iniciativa. La Voz de Almería, 30 de enero de 1985, p. 4.

Una iniciativa feliz. La Independencia, 14 de julio de 1934, p. 1.

\section{FUENTES LEGISLATIVAS}

DECRETO 1462/1964, de 6 de mayo por el que se concede el reconocimiento oficial en el grado de Conservatorio Elemental a las enseñanzas de la Escuela Municipal de Música de Jerez de la Frontera (Cádiz), BOE n. ${ }^{\circ}$ 118, Madrid, 16 de mayo de 1964, p. 6.362.

DECRETO 237/1988, de 14 de junio, por el que se acuerda el cese de actividades académicas del conservatorio de Música y Danza no estatal de grado elemental de Almería. Boletín Oficial de la Junta de Andalucía (BOJA) no 58, Sevilla, 22 de julio de 1988, p. 3.350.

Gaceta de Madrid, 6 de noviembre de 1886.

ORDEN de 19 de agosto de 1991, por la que se modifican las enseñanzas en el Conservatorio Profesional de Música de Almería. BOJA no 89, 8 de octubre de 1991, p. 8.779 .

ORDEN de 29 de junio de 1993, por la que se autoriza la denominación de Real Conservatorio Profesional de Música, al Conservatorio Profesional de Música de Almería. BOJA no 86, 7 de agosto de 1993, p. 7.642.

ORDEN de 12 de julio de 1996, por la que se autorizan nuevas especialidades en los Conservatorios de Música de la Comunidad Autónoma de Andalucía. BOJA nº 93, 13 de agosto de 1996, pp. 10.021-10.022.

ORDEN de 30 de julio de 1997, por la que se autorizan nuevas especialidades en los Conservatorios de Música de la Comunidad Autónoma de Andalucía. BOJA nº 108, 16 de septiembre de 1997, pp. 11.409-11.410. 
ANTECEDENTES, CREACIÓN Y ORGANIZACIÓN ESCOLAR DEL

Conservatorio de Música y DanZa no estatal de Almería (1982-1987)

ORDEN de 4 de junio de 1998, por la que se autorizan nuevas especialidades en los Conservatorios de Música de la Comunidad Autónoma de Andalucía. BOJA nº 75, 7 de julio de 1998, p. 8.422 .

REAL DECRETO 3115/1977, de 7 de noviembre, por el que se nombra Delegado Provincial del Ministerio de Educación y Ciencia en Almería a don José Ramos Santander. BOE no 293, Madrid, 8 de diciembre de 1977, p. 26.962.

Ministerio de Educación y Ciencia. Real Decreto 304/1983, de 19 de enero, Boletín Oficial del Estado (BOE) no 43, Madrid, 19 de febrero de 1983, p. 4.785.

BOJA no 108, Sevilla, 05.12.1986, pp. 3.765-3.766 y Real Decreto 3936/82, de 29 de diciembre sobre traspaso de funciones y servicios de Administración del Estado a la Comunidad Autónoma de Andalucía en materia de educación, BOE n 19, 22 de enero de 1983, pp. 1.663-1.664.

DECRETO 8/1988, de 20 de enero, por el que se crea la Escuela de Arte Dramático y Danza (Sección Danza) en Almería. BOJA, nº 9, 5 de febrero de 1988, p. 405.

DECRETO 305/1994, de 20 de septiembre, por el que se crea el Conservatorio Profesional de Danza de Almería y se integra en el mismo la sección de danza de la Escuela de Arte Dramático y Danza de Almería. BOJA no 150, 24 de septiembre de 1994, pp. 11.315-11.316.

ORDEN de 13 de julio de 2012, BOJA no 154, 7 de agosto de 2012, pp. 42-43.

Fecha de recepción: 11 de octubre de 2019

Fecha de aceptación: 13 de diciembre de 2019 